\title{
What is the evidence for the use of biologic or biosynthetic meshes in abdominal wall reconstruction?
}

\author{
F. Köckerling ${ }^{1}$ - N. N. Alam ${ }^{2}$-S. A. Antoniou ${ }^{3} \cdot$ I. R. Daniels ${ }^{4}$ - F. Famiglietti ${ }^{5} \cdot$ R. H. Fortelny ${ }^{6} \cdot$ M. M. Heiss ${ }^{7}$. \\ F. Kallinowski ${ }^{8} \cdot$ I. Kyle-Leinhase ${ }^{9} \cdot$ F. Mayer $^{10} \cdot$ M. Miserez $^{5} \cdot$ A. Montgomery ${ }^{11} \cdot$ S. Morales-Conde ${ }^{12} \cdot$ F. Muysoms $^{9}$. \\ S. K. Narang ${ }^{4} \cdot$ A. Petter-Puchner ${ }^{13} \cdot$ W. Reinpold ${ }^{14} \cdot$ H. Scheuerlein ${ }^{15} \cdot$ M. Smietanski $^{16,20} \cdot$ B. Stechemesser ${ }^{17}$. \\ C. Strey ${ }^{18} \cdot$ G. Woeste ${ }^{19} \cdot$ N. J. Smart ${ }^{4}$
}

Received: 19 September 2017 / Accepted: 11 January 2018 / Published online: 31 January 2018

(c) The Author(s) 2018. This article is an open access publication

\begin{abstract}
Introduction Although many surgeons have adopted the use of biologic and biosynthetic meshes in complex abdominal wall hernia repair, others have questioned the use of these products. Criticism is addressed in several review articles on the poor standard of studies reporting on the use of biologic meshes for different abdominal wall repairs. The aim of this consensus review is to conduct an evidence-based analysis of the efficacy of biologic and biosynthetic meshes in predefined clinical situations.

Methods A European working group, "BioMesh Study Group", composed of invited surgeons with a special interest in surgical meshes, formulated key questions, and forwarded them for processing in subgroups. In January 2016, a workshop was held in Berlin where the findings were presented, discussed, and voted on for consensus. Findings were set out in writing by the subgroups followed by consensus being reached. For the review, 114 studies and background analyses were used. Results The cumulative data regarding biologic mesh under contaminated conditions do not support the claim that it is better than synthetic mesh. Biologic mesh use should be avoided when bridging is needed. In inguinal hernia repair biologic and biosynthetic meshes do not have a clear advantage over the synthetic meshes. For prevention of incisional or parastomal hernias, there is no evidence to support the use of biologic/biosynthetic meshes. In complex abdominal wall hernia repairs (incarcerated hernia, parastomal hernia, infected mesh, open abdomen, enterocutaneous fistula, and component separation technique), biologic and biosynthetic meshes do not provide a superior alternative to synthetic meshes.
\end{abstract}

Conclusion The routine use of biologic and biosynthetic meshes cannot be recommended.

Keywords Biologic meshes $\cdot$ Biosynthetic meshes $\cdot$ Complex ventral hernias $\cdot$ Contaminated surgical field $\cdot$ Bridging

\section{Introduction}

There is a rising demand for materials to replace or augment a patient's native tissue when it has been compromised [1]. These products are divided into two groups: synthetic and biologic meshes [1]. Synthetic meshes can be either permanent or absorbable [1]. The development of absorbable and biologic meshes was triggered by the complications of using

A comment to this article is available at https://doi.org/10.1007/ s10029-018-1736-x.

F. Köckerling

ferdinand.koeckerling@vivantes.de

Extended author information available on the last page of the article permanent meshes [1]. Contamination of the surgical field poses a dilemma as the use of permanent synthetic material is historically considered contraindicated given the risk of postoperative infective complications and need for mesh removal [2]. The introduction of biologic or absorbable synthetic meshes has provided an alternative [2]. Derived from biologic (human, bovine, or porcine) sources or absorbable synthetic material, these meshes theoretically incorporate into native tissue and possess the ability to resist infection [2]. Although none of the biologic meshes have US Food and Drug Administration approval for use in an infected field and even though there is a paucity of controlled data, they have become the method of choice in many institutions across Europe and the United States over the past several years [3]. Because the outcomes of biologic meshes are perceived to 
be better than those for synthetic non-absorbable meshes, the use of biologic meshes increased exponentially without clear evidence of efficacy [4]. Although many surgeons have adopted the use of biologic meshes in complex situations, others have questioned the use of these products [3]. Criticism is addressed in several review articles on the poor standard of studies reporting on the use of biologic meshes for different abdominal wall repairs [5-21]. In view of this controversial debate about the benefits of biologic meshes, in an invited commentary in the journal, "Hernia" Agneta Montgomery refers to "The battle between biologic and synthetic meshes in ventral hernia repair" [22]. This controversial debate on what mesh to use in which patient in any specific situation became even more complex with the introduction of the biosynthetic meshes in addition to the already existing synthetic and biologic meshes. Biosynthetic meshes were developed as a possible cost-effective alternative to the biologic meshes.

The aim of a group of hernia experts (BioMesh Study Group) was to conduct an evidence-based review of the efficacy of biologic and biosynthetic meshes in predefined clinical situations. The scope of this analysis was focused on guidelines, meta-analyses, systematic reviews, and prospective randomized trials, but also lower level of evidence was accepted when data were missing on specific tasks.

\section{Methods}

In the early 2015, a European working group, "BioMesh Study Group", composed of invited surgeons with a special interest in surgical meshes met to analyze the available evidence on the use of biologic and biosynthetic meshes. Key questions were formulated by the BioMesh Study Group and forwarded for processing in subgroups. In January 2016, a workshop was held in Berlin where the findings were presented, discussed, and voted on for consensus. Findings were set out in writing by the subgroups followed by consensus being reached within the BioMesh Study Group. For the review, 114 studies and background analyses were used. The conclusion at the end of each set of questions reflects the consensus reached by the members. At the end of the conclusions, the level of evidence according to the Grade system [23] is given for the studies included in the reviews to answers the key questions.

\section{Characteristics of biologic and absorbable synthetic (biosynthetic) meshes}

Biologic meshes derived from the collagen-rich tissues of human, porcine, or bovine sources [24]. The tissues are decellularized with sodium deoxycholate or a similar solvent, which yields a matrix of collagen, elastin, and laminin that serves as supporting scaffold for cellular repopulation and neovascularization. These acellular scaffolds may also be additionally cross-linked, which inhibits collagen degradation by blocking collagenase-binding sites, thereby allowing the mesh to maintain its structure for a longer period with slower incorporation into the adjacent tissue [24].

Although the basic composition of each biologic mesh is the same (i.e., a collagen matrix), the meshes vary in tensile strength, rate of incorporation, and resistance to infection [24]. The more commonly used biologic meshes (Table 1) are human acellular dermal matrix, porcine small intestine submucosa, porcine dermis, and bovine pericardium [24].

The most important step is the biologic mesh integration followed by remodeling new collagen deposition and tissue regeneration [8]. During this process, the implanted mesh is often reabsorbed by the host. Unfortunately, this process is poorly understood and is often difficult to determine and quantify/measure [8].

The absorbable synthetic mesh Bio-A (Gore) is a copolymer of polyglycolic acid and trimethylene carbonate in a three-dimensional matrix, which completely degrades in approximately 6 months [25]. Phasix (Bard/Davol) is a macroporous, fully absorbable synthetic mesh that consists of co-knitted absorbable poly-4-hydroxybutyrate and Phasix ST (Bard/Davol) is a composite mesh with additional polyglycolic acid fibers coated with a chemically modified sodium hyaluronate, carboxymethylcellulose, and polyethylene glycol-based hydrogel on the visceral surface [26]. It has a complete resorption time of 12-18 months [25].

Table 1 Biological meshes currently on the market

\begin{tabular}{llll}
\hline Name & Manufacturer & Cross-linked & Source \\
\hline Alloderm & Life cell & No & Human dermis \\
Strattice & Life cell & No & Porcine dermis \\
Permacol & Covidien & Yes & Porcine dermis \\
Veritas & Baxter & No & $\begin{array}{c}\text { Bovine pericar- } \\
\text { dium }\end{array}$ \\
Collamend & BARD & Yes & Porcine dermis \\
Allomax & BARD & No & Human dermis \\
Xen matrix & BARD & No & Porcine dermis \\
Surgimend & TEI biosciences & No & Bovine dermis \\
XCM Biologic & J \& J & No & Porcine dermis \\
Flex HD & J \& J & No & Human dermis \\
Tutomesh & RTI surgical & No & Bovine pericar- \\
& & & dium \\
FortaGen & Organogenesis & No & Porcine intestine \\
Fortiva & RTI surgical & No & Porcine dermis \\
Cortiva & RTI surgical & No & Human dermis \\
Biodesign/sur- & Cook medical & No & Porcine intestine \\
$\quad$ gisis & & & No \\
Epiflex & DIZG & Human dermis \\
Cellis & Mecellis biotech & No & Porcine dermis \\
\hline
\end{tabular}


The macroporous multifilament absorbable synthetic mesh TIGR Matrix Surgical mesh (Novus Scientific) has also been recently introduced on to the market. It consists of two types of fibers (fast and slow-resorbing fiber) and is a copolymer of lactide and trimethylene carbonate and completely resorbs in 3 years [26].

\section{Are biologic and biosynthetic meshes more resistant to infection than synthetics?}

One of the main marketed described advantages of biologic meshes is its ability to be used in contaminated fields without the fear of infection and need for explantation [27]. In theory, the vascular ingrowth that occurs with a biologic mesh allows the host immune system to fight infection, as opposed to synthetic meshes where no true ingrowth occurs [27]. In a critical review of biologic meshes used in ventral hernia repairs under contaminated conditions, Primus et al. pointed out that all reviews on biologic meshes supported biologic mesh use, especially in the setting of contaminated fields [18]. Yet, the primary literature included in reviews consisted entirely of low level of evidence (case series and case reports). The conclusion was that cumulative data regarding biologic mesh use in ventral hernia repair under contaminated conditions do not support the claim that it is better than synthetic mesh used under the same conditions.

Data from the National Surgical Quality Improvement Program (NSQIP) of 33,832 patients with ventral hernia repair using mesh in clean-contaminated and contaminated surgical fields compared to clean cases showed a significantly higher odds ratio (OR) of having one or more postoperative occurrences with 3.56 [3.25-3.89] and 5.05 [1.78-12.41], respectively [28]. There was a significantly increased OR of superficial surgical site infections (SSI) (OR 2.53), deep SSI (OR 3.09) and wound disruption (OR 4.41) for clean-contaminated cases compared to clean cases [28].

A systematic review on synthetic and biologic meshes for abdominal wall reinforcement in contaminated fields found a total of 32 studies that met inclusion criteria. Mean sample size was 41.4 (range 10-190) [29]. Overall study quality was low. Pooled wound infection rate was $31.6 \%$ (95\% CI 14.5-48.7) with biologic and 6.4\% (95\% CI 3.4-9.4) with synthetic non-absorbable meshes in clean-contaminated patients. In contaminated and/or dirty fields, wound infection rates were similar, but pooled hernia recurrence rates were $27.2 \%$ (95\% CI 9.5-44.9) with biologic and 3.2\% (95\% CI 0.0-11.0) with synthetic non-absorbable. The authors concluded that the available evidence is limited, but does not support the superiority of biologic over synthetic nonabsorbable meshes in contaminated fields [29].

In another systematic review by Darehzereshki et al. [30] only including case series with the use of biologic meshes in clean surgical fields, they found significantly fewer infectious wound complications $(p<0.00001)$ for biologic in comparison to synthetic meshes.

The systematic review by Atema et al. [2] showed no benefit of biologic over synthetic mesh for repair of potentially contaminated hernias with comparable surgical site complication rates. Overall surgical complication rate was $50 \%$ and mesh removal rate was $1 \%$ [2]. The systematic review by Cross et al. [3] comprised 16 studies with 554 patients with contaminated surgical fields. The overall infection rate was $25 \%$. The authors concluded that caution should be used when using biologic mesh products in infected fields, because there is a paucity of controlled data and none have US Food and Drug Administration approval for use in infected fields [3].

A retrospective analysis of a prospective database reviewed 761 ventral hernia repairs with suture, synthetic, or biological mesh in contaminated surgical fields [31]. The unadjusted outcome for surgical site infections $(15.1 \%, 17.8 \%, 21.0 \% ; p=0.280)$ was not statistically different between groups [31]. A matched pair analysis of 40 ventral hernia repairs with biological mesh compared to 40 patients having synthetic mesh repair in complicated situations showed no significant differences in surgical site infection (20\% vs. $35 \%$; $p=0.29)$ [32].

In a retrospective study comparing 34 contaminated abdominal wall repairs with biological mesh with 24 with synthetic mesh found an overall infection rate of $50 \%$ vs. $29.2 \%(p=0.18)$ [33].

In a multicenter, retrospective review of patients undergoing open ventral hernia repair in clean-contaminated/ contaminated fields (69 biologic and 57 synthetic meshes), there were $13(22.8 \%)$ surgical site events in the synthetic cohort compared to $29(42.0 \%)$ in the biologic cohort $(p=0.024)$ [34]. Similarly, surgical site infections were less frequent in the synthetic group, with 7 (12.3\%) versus $22(31.9 \%) ; p=0.01$. The authors concluded that overall the findings not only support suitability of synthetic mesh in contaminated settings but also challenge the purported advantage of biologics in clean-contaminated/contaminated ventral hernia repairs [34].

Ko et al. [35] analyzed separately results in patients without contamination (Alloderm $n=13$; PP $n=23$ ). Major complications were comparable (15\% vs. $17 \%$ ), but minor wound complications were lower in the biologic mesh group ( $8 \%$ vs. $17 \%$ ). Recurrence was seen in $38.5 \%$ of Alloderm and only in $4 \%$ of PP repaired patients.

El-Gazzaz [36] performed a retrospective study of 25 patients with ventral hernia and concomitant bowel surgery comparing biologic mesh with intraabdominal PP or polytetrafluoroethylene. Wound complications and mesh infection/excision rates did not show advantage of biologic mesh. 
Nockolds et al. [37] evaluated retrospectively 23 patients with complex hernias (width 8-17 cm, VHWG III/IV) with 7 patients having an enterocutaneous fistula. A total of 17 had biologic mesh (Biodesign $n=14$; cross-linked porcine dermis $n=3$ ) and 6 had a synthetic (PP). Around $60 \%$ had an onlay mesh and $60 \%$ had an anterior CST achieving midline closure in $87 \% .10,15$, and $10 \%$, respectively, in the biologic mesh group developed wound dehiscence, infection or a recurrence. The numbers in the synthetic mesh group were $17 \%$ for each of the outcome parameters.

Gurrado et al. [38] evaluated retrospectively a group of 76 patients with midline defects (mean defect size $150 \mathrm{~cm}^{2}$ ) and fascial closure ( \pm relaxing incisions). Clean contamination was differentiated from contaminated/dirty settings. Sixteen percent of the patients in the synthetic and $61 \%$ in the biologic mesh group were contaminated/dirty. Synthetic meshes were PP or polyester and biologic mesh was bovine pericardium. Onlay mesh was used in about $2 / 3$ and retromuscular mesh in the remainder, equally divided between both groups. Wound infection rates were 53\% versus 3\% in the synthetic versus biologic group, seroma incidence $34 \%$ versus none, and recurrence rate at 1-year follow-up $16 \%$ versus none. Complications in the synthetic mesh group were almost exclusively seen in the onlay group.

In a study by Sahoo et al. [39], a total of 438 patients with clean-contaminated and contaminated wounds were considered for comparative analysis of 30-day outcomes. Within this cohort, 58 (13.2\%) patients underwent ventral hernia repair with biosynthetic mesh (Phasix, Bio-A) and 380 (86.8\%) with polypropylene mesh. Propensity-matchedanalysis showed no significant difference between biosynthetic and polypropylene mesh groups for 30-day surgical site occurrence $(20.7 \%$ vs. $16.7 \%$; $p=0.49)$ or unplanned readmission ( $13.8 \%$ vs. $9.8 \% ; p=0.4)$. However, surgical site infections ( $22.4 \%$ vs. $10.9 \% ; p=0.03)$, surgical site occurrences requiring procedural intervention $(24.1 \%$ vs. $13.2 \% ; p=0.049)$ and reoperation rates $(13.8 \%$ vs. $4.0 \%$; $p=0.009)$ were significantly higher in the biosynthetic group.

In a retrospective case series by Madani et al. [40], 46 hernias were repaired with biologic mesh in clean-contaminated $(n=16 ; 35 \%)$, contaminated $(n=11 ; 24 \%)$, and dirty $(n=19 ; 41 \%)$ fields. Incidences of surgical site events and surgical site infection were $43 \%(n=20)$ for contaminated and $56 \%(n=25)$ for dirty fields.

In a study by Sbitany et al. [41], a prospectively maintained database was reviewed for all patients undergoing repair with component separation technique with biologic mesh in potentially contaminated or infected ventral hernias. The overall postoperative wound infection rate was $15 \%$. No mesh was removed due to perioperative infection [41].

A retrospective case series with 140 patients with biologic mesh repair of complex abdominal wall hernias showed a wound complication rate of $30.7 \%$ and a mesh removal rate of $10 \%$ [42].

In a retrospective study with 80 patients with contaminated field and major complex abdominal wall repair using biological mesh, 36 patients (45\%) developed a wound infection [43]. None required mesh removal. The authors concluded that repair of challenging and contaminated abdominal wall defects can be done effectively with biologic mesh and component separation technique without the need for mesh removal despite wound infections [43].

In a retrospective, comparative study of the use of Phasix versus biologic mesh in complex abdominal wall reconstruction, the postoperative infection rates were $31 \%$ versus $12.9 \%(p=0.073)$ [44].

In a study by Rosen et al. [45] with contaminated ventral hernia repair using Bio-A, the surgical site infection rate was $18.3 \%$. The authors concluded that biosynthetic absorbable meshes offer an alternative to biologic and permanent synthetic meshes in these complex situations.

In an expert consensus guided by systematic review on ventral hernia management, a statement is made that biological meshes have been safely utilized in abdominal wall reconstruction with few mesh explantations [46]. However, their role still needs to be defined. No data exist on the safety, efficacy, or effectiveness of bioabsorbable synthetic meshes [46].

\section{Conclusion}

The cumulative data regarding biologic and biosynthetic mesh use in ventral hernia repair under contaminated conditions do not support the claim that it is better than synthetic mesh used under the same conditions [18]. The available evidence is limited in quantity and quality, but it does not support the superiority of biologic over synthetic non-absorbable meshes in contaminated fields [29] (level of evidence according to the GRADE system [LoE GRADE]: moderate).

\section{Can biologic or biosynthetic meshes be used for bridging in ventral hernia repairs?}

Mesh implantation during abdominal wall reconstruction decreases ventral hernia recurrence rate substantially and has become the recommended method for repair [47]. The onlay position or bridging the gap is less favorable mesh locations and results in the highest recurrence rates [47]. In a meta-analysis, component separation with primary fascial closure and mesh reinforcement was associated with a lower risk of surgical site occurrence and recurrence compared with bridged repairs [48]. When considering a biologic mesh repair, the position of the mesh has also a major impact on recurrence rate. When biologic 
mesh is sewn to the edge of the fascia and used as a bridge, recurrence rates are as high as $80 \%$ [1]. When the fascia can be reapproximated and the mesh used to reinforce the repair, the recurrence rate drops to approximately $20 \%$ [1].

The systematic review by Albino et al. [47] summarizes the main findings from each of the individual studies including 1181 patients having a ventral hernia repair using biologic mesh. A bridging position of a biologic mesh resulted in the highest rate of hernia recurrences $(56 \%)$ compared to onlay (20\%), underlay (16\%), and retrorectus position $(8 \%)(p=0.03)$ [47].

In another systematic review, component separation followed by primary fascial closure was compared to a bridged repair for ventral hernia [48]. Four studies were identified. The pooled recurrence rate was $49.0 \%$ (range $20.5-72.7 \% ; n=102$ ) for bridged repair and $11.1 \%$ (range $7.7-18.2 \% ; n=341$ ) for primary fascial closure [48].

In the systematic review by Atema et al. [2] including three studies with bridged repair in $47-100 \%$ of cases, a hernia recurrence rate of $24 \%$ was found.

The LAPSIS trial was a four-armed randomizedcontrolled European multicenter study comparing open retromuscular (mesh augmentation technique) versus laparoscopic repair (mesh bridging technique) [49]. A non-cross-linked biologic mesh versus classical synthetic mesh for clean primary ventral and incisional hernia with a diameter of $4-10 \mathrm{~cm}$ was used in both groups. Inclusion of patients was prematurely stopped. The Independent Data Monitoring Committee of the trial recommended this action because of a higher recurrence rate in the biological mesh compared with the synthetic mesh group at interim analysis. Based on the "as-treated" population of 257 patients, the exploratory analysis (median followup 1 year) showed that implantation of a biologic mesh resulted in a higher rate of early recurrence in each of the study arms: $19 \%$ recurrence for biologic mesh versus $5 \%$ for synthetic after laparoscopic repair, and $11 \%$ versus $3 \%$ after open repair. The authors concluded that care should be taken and bridging of hernia defects with biologic mesh should be avoided.

In a retrospective study, Basta et al. [50] reported on 37 patients undergoing complex ventral hernia repair using a biologic mesh for bridging. With an average of 8.2-month follow-up, the recurrence rate was $18.9 \%$ [50].

In a retrospective study by Giordano et al. [51], a total of $484(90 \%)$ patients underwent mesh-reinforced abdominal wall reconstruction without bridging and 51 (10\%) underwent a bridging repair. A cellular dermal matrix was used in $98 \%$ of the bridged repairs and in $96 \%$ of the reconstructions without bridging. Bridged repairs had a greater hernia recurrence rate of $33.3 \%$ versus $6.2 \%$ without bridging $(p<0.001)$ [51].

\section{Conclusion}

Biologic mesh use should be avoided when bridging is needed in ventral hernia repairs due to the very high risk of a recurrence (LoE GRADE: moderate).

\section{Biologic and biosynthetic meshes for inguinal hernia repair}

In the European Hernia Society guidelines on the treatment of inguinal hernia in adult patients the use of a tensionfree, synthetic non-absorbable flat mesh technique is recommended on the evidence-level grade A [52]. "Material reduced" meshes have some advantages with respect to chronic pain and foreign body sensation in the first year(s) after open inguinal hernia repair. There is, however, no difference in the incidence of severe chronic pain [53]. This advantage has not been shown in endoscopic repair [53]. In the guidelines for laparoscopic (TAPP) and endoscopic (TEP) treatment of inguinal hernia of the International Endohernia Society, a statement is given that lighter meshes with larger pores do not lead in the long-term comparison to improvements of the quality of life or a reduction of discomfort of statistical significance $[54,55]$. According to the European Association of Endoscopic Surgeons Consensus Development Conference repair of incarcerated, non-reducible groin hernias have to be done urgently and can be performed with an endoscopic technique [56]. Mesh placement during surgery for strangulated groin hernia is possible in clean-contaminated situations (i.e., in case of a bowel resection) [56].

Biologic or biosynthetic meshes are a potential alternative to the synthetic meshes with the aim to avoid complications [57]. In a systematic review and meta-analysis, Nie et al. [58] compared three randomized-controlled trials (RCTs) encompassing 200 patients with porcine small intestinal submucosa (SIS) versus polypropylene in open inguinal hernia repair. There was no significant difference in recurrence (OR 2.03; 95\% CI 0.37-11.23; $p=0.4$ ), hematomas (OR 3.55; 95\% CI 0.95-13.22; $p=0.06$ ), postoperative pain within 30 days (OR 0.63 ; 95\% CI $0.19-2.06 ; p=0.45$ ), or postoperative pain after 1 year (OR 0.32; 95\% CI 0.07-1.36; $p=0.12$ ) between the two groups. The incidence of discomfort was significantly lower (OR 0.09; 95\% CI 0.02-0.36; $p=0.0006)$ in the SIS group. However, the SIS group experienced a significantly higher incidence of seroma (OR 3.96; 95\% CI 1.16-13.50; $p=0.03$ ) [57].

Fang et al. [59] compared in a meta-analysis with a total of 382 patients in 5 RCTs biologic versus synthetic mesh in open inguinal hernia repair. The two groups did not significantly differ in chronic pain (OR 0.54 ; 95\% CI $0.29-1.02 ; p=0.06$ ) or recurrence (OR 2.15; 95\% CI 3.39-11.74; $p=0.38$ ). The incidence of seroma 
trended higher in biologic mesh group (OR 2.67; 95\% CI $1.12-6.35 ; p=0.03)$. Operating time was significantly longer with biologic mesh (Mean difference $=6.27$; 95\% CI $0.57-11.97 ; p=0.03)$. There was no significant difference in hematomas (OR 1.62; 95\% CI 0.73-3.62; $p=0.23$ )

In a systematic review of the literature including 7 RCTs no difference in the recurrence rate was found, but differences in the postsurgical pain incidence in favor of the biologic mesh [57]. The biologic mesh was used successfully in a potentially contaminated setting [57].

The systematic review and meta-analysis of RCTs and non-RCTs by Öberg et al. [60] showed no difference in recurrence rate with a median follow-up of 18 months and chronic pain rates (1-year follow-up) between absorbable biologic/synthetic and permanent synthetic meshes.

\section{Conclusion}

Biologic and biosynthetic meshes do not have a clear advantage over the synthetic meshes and can, therefore, not be recommended for routine use in elective groin hernia repair. They can be considered in situations with contaminated and dirty surgical fields (LoE GRADE: moderate).

\section{Prevention of incisional hernias with biologic or biosynthetic meshes}

The use of primary mesh augmentation for abdominal wall closure is associated with significant lower incidence of incisional hernia compared to primary suture [61]. In a large multicenter RCT, a significant reduction in incidence of incisional hernia was achieved with onlay mesh reinforcement compared with sublay mesh reinforcement and primary suture only without increase of surgical site infection [62, 63]. In the EHS guidelines on the closure of abdominal wall incisions, prophylactic mesh augmentation for an elective midline laparotomy in a high-risk patient to reduce the risk of incisional hernia is suggested [64]. No recommendation on the type of mesh for prophylactic mesh augmentation can be given due to lack of data [64].

In a systematic review on prevention of incisional hernias with biologic mesh, only two RCTs, two case-control studies, and two case series were identified [65]. The studies were very heterogeneous. After qualitative assessment, the conclusion was that the level of evidence on the efficacy and safety of biologic meshes for prevention of incisional hernias is very low. No comparative studies were found comparing biologic mesh with permanent synthetic meshes for the prevention of incisional hernia [65].

\section{Conclusion}

There is no evidence supporting the use of biologic or biosynthetic meshes for the prevention of incisional hernia when closing a laparotomy in high-risk patients or in stoma reversal wounds. There is no evidence to support the use of biosynthetic meshes in preference to permanent synthetic meshes in clean or clean-contaminated surgery ( $\mathrm{LoE}$ GRADE: low).

\section{Prevention of parastomal hernias by biological or biosynthetic mesh reinforcement}

On reviewing four meta-analyses, it was found that mesh placed prophylactically at the time of stoma creation reduced the rate of parastomal hernias without an increase in meshrelated complications [66-69]. In the majority of included studies, permanent synthetic meshes have been used for prophylaxis of a parastomal hernia.

In a systematic review on prevention of a parastomal hernia focusing on biological mesh reinforcement, only two randomized-controlled trials (RCT) and two case-controlled studies were found [70]. In one RCT and two case-controlled studies, respectively, there was a significant smaller incidence of parastomal herniation as well as a similar complication rate compared to the control group [70]. Only in one RCT, no significant difference regarding the incidence of parastomal hernia was reported with comparable complication rates [70].

\section{Conclusion}

The quality of data does not support a significant risk reduction of parastomal hernia development by biologic mesh reinforcement of a permanent stoma at the primary operation. The use of biologic meshes for prophylaxis of a parastomal hernia should not be performed outside clinical studies (LoE GRADE: low).

\section{Biologic and biosynthetic meshes for complex abdominal wall hernia repair}

A clear definition of "complex abdominal wall hernia (CAWH)" is missing, though the term is often used [71]. Three consensus meetings were convened by surgeons with expertise in complex abdominal wall hernias, aimed at laying down criteria that can be used to define "complex hernia" patients, and to divide patients in severity classes [71]. Emergency operations with bowel resection, open abdomen, parastomal hernias, current mesh infections, enterocutaneous fistulas, wound environment with surgical wound class 
III (contaminated) or IV (dirty), and large-sized abdominal wall hernias $\geq 10 \mathrm{~cm}$ in width beside others fulfil the criteria of a "complex abdominal wall hernia" [71].

The role of biologic and biosynthetic meshes for these indications will now be explored in greater depth below. The basic problems encountered when using biologic or biosynthetic meshes in the setting of an infected abdominal wall and for bridging have already been discussed above. The various clinical situations will now be addressed in detail below.

\section{Open and laparo-endoscopic repair of incarcerated abdominal wall hernias by the use of biologic and biosynthetic meshes}

In the new international guidelines of the HerniaSurge group, it is recommended not to use mesh during emergent groin hernia repair in a contaminated or dirty surgical field [72]. Little evidence exists comparing the implantation of mesh of various types in non-clean surgical fields. Largepore monofilament polypropylene, and biologic and biodegradable meshes have unknown effects on mesh infection risks [72]. As surgical field contamination status worsens, it is recommended that mesh use be ever more conscientiously considered. If mesh is used, the risk/benefit ratio must be carefully contemplated [72].

There are limited data on emergency ventral hernia repair [46]. Short-term and long-term outcomes are worse compared with elective repair [46]. Factors that are important in deciding which type of repair to perform include patient stability, patient comorbidities, the degree of contamination, and the presence of bowel obstruction or edema [46]. Surgeons should be cautious and use discretion in creating flaps or performing other complex procedures such as component separation in this setting [46].

In a systematic review of the use of biologic and biosynthetic meshes in incarcerated abdominal wall hernia repair, only five retrospective cohort studies, two case-controlled studies, and six case series could be found [73]. The limited evidence demonstrated a very low incidence of infection and recurrence of porcine intestine submucosa in laparoscopic IPOM with defect closure in infected fields [73] and acellular dermal matrix by open approach [73]. Both studies achieved acceptable outcome in a follow-up of at least 3.5 years compared to the use of synthetic mesh in this highrisk population [73].

In the guidelines of the World Society of Emergency Surgery concerning emergency surgery of complicated abdominal wall hernias with potentially contaminated surgical field caused by intestinal strangulation and/or concurrent bowel resection, direct suture is recommended when the hernia defect is small [74]. Synthetic mesh repair may be performed, but with caution. Biologic meshes may be a valid option but merit detailed cost-benefit analysis [74].

According to the guidelines for laparoscopic treatment of ventral and incisional abdominal wall hernias of the International Endohernia Society [75-77], laparoscopic repair of incisional and ventral hernias with non-crosslinked biologic meshes in an infected or potentially contaminated surgical field may be a viable option if the hernia defect is closed primarily.

Conclusion Up to now, there is lack of studies comparing the use of biologic or biosynthetic versus synthetic meshes in contaminated or dirty surgical fields of incarcerated and/or strangulated abdominal wall hernia repair. The use of biologic and biosynthetic meshes is an option in contaminated or dirty fields of incarcerated and/or strangulated abdominal wall hernia repair when defect closure is possible (LoE GRADE: very low).

\section{Repair of parastomal hernias with biologic or biosynthetic meshes}

Suture repair of parastomal hernias should be abandoned because of increased recurrence rates [78]. The use of mesh in parastomal hernia repair significantly reduces recurrence rates and is safe with a low overall rate of mesh infection [78]. In laparoscopic repair, the Sugarbaker technique is superior over the key-hole technique showing fewer recurrences $[78,79]$. In open techniques for parastomal hernia repair, there is insufficient evidence to determine which mesh technique (onlay, sublay, and underlay) is most successful in terms of recurrence rates and morbidity [80]. Four retrospective studies with a combined enrolment of 57 patients were included in a systematic review of biologic mesh use in parastomal hernia repair. Recurrence occurred in $15.7 \%$ of patients and wound-related complications in $26.2 \%$ [81]. No mortality or mesh infection was reported [81]. The authors concluded that the use of reinforcing or bridging biologic meshes during parastomal hernia repair results in acceptable rates of recurrence and complications. However, given the similar rates of recurrence and complications achieved using synthetic meshes in this scenario, the evidence does not support use of biologic meshes.

Conclusion Biologic meshes do not provide a superior alternative to synthetic meshes for parastomal hernia repair, while at the same time being less cost-effective for this indication. Biologic meshes cannot be considered an alternative to synthetic meshes for elective parastomal hernia repair (LoE GRADE: very low). 


\section{Replacement of an infected synthetic by a biologic or biosynthetic mesh}

A systematic review identified three different options to treat an infected synthetic mesh: removal of the synthetic mesh alone, replacement with either a new synthetic, or a new biologic mesh [82]. Removal of the mesh alone is an option limited to inguinal hernias [82]. In ventral/incisional hernias, the use of a biological mesh for replacement resulted in a very high recurrence rate if bridging was required [82]. Either a synthetic (onlay) or a biologic mesh seems to work as a replacement when fascial closure can be achieved [82]. Reports on replacement with a biologic mesh are few and of low quality. Only 90 patients were identified. The overall wound infection rate was $39 \%$ and the recurrence rate $27 \%$ with a median follow-up of 2 years. The wound complications will resolve on local treatment with no report on mesh removal of median 2-year follow-up. Either an onlay or retromuscular position seems to work [82].

In another systematic review, a hernia recurrence rate of $21.4 \%$ was achieved when the mesh was placed in a retrorectus or underlay position [83]. Bridged repairs were highly prone to recurrence $(88.9 \% ; p=0.001)$ [83].

Conclusion It is recommended not to use a biologic mesh for bridging in replacement of an infected synthetic mesh due to the high risk of recurrence. Either a synthetic (onlay) or biologic mesh seems to work as a replacement of an infected synthetic mesh if the fascia defect can be closed in ventral and incisional hernia (LoE GRADE: very low).

\section{Management of the open abdomen for definitive closure using a biologic or biosynthetic mesh}

An open abdomen is a widely performed practice in patients with severe sepsis or trauma [84]. A temporary abdominal closure is indispensable to reduce the incidence of complications [84]. The ultimate goal of temporary abdominal closure is to achieve definitive fascial closure [84]. To improve survival rates, the early fascial closure is routinely preferred to achieve a permanent abdominal closure [84]. Early fascial closure is defined as a reapproximated closure of abdominal fascia within the window of 2-3 weeks after an open abdomen [84]. The early fascial closure rate ranged from 29 to $85 \%$ [84]. Vacuum-assisted fascial closure was described in $85 \%$ [84]. The mean duration to a definitive abdominal closure ranged from 2.2 to 14.6 days in early fascial closure rate [84].

Fascial traction reduces the need of a mesh for definitive closure. Cocollini et al. also reported on definitive fascial closure to be achievable in up to $90 \%$ [85]. Early closure seems to be a key point for success. Closure exceeding 8 days seems to result in a progressively increasing complication rate. When definitive closure cannot be achieved by suturing, a mesh to bridge the gap is needed. Either a synthetic or a biologic mesh has been used and reported on.

An updated version of the World Society of Abdominal Compartment Syndrome (WSACS) guidelines was published in 2015, including consensus definitions and recommendations for clinical practice using the GRADE methodology [86]. Twelve clinical relevant questions were raised out of which one (with subquestions) was on the use of biologic meshes for definitive closure. The question was: "How should we avoid abdominal compartment syndrome or how should we deal with the open abdomen? Does early closure with biologic meshes improve patient outcomes compared to strategies that do not use biologic meshes which thus accept skin graft closures and delayed reconstruction in critically ill adults with open abdomen in critical care units?"

Recommendations/suggestions made by the World Society of Abdominal Compartment Syndrome were as follows [85]:

- "We recommend that among ICU patients with open abdominal wounds, conscious and/or protocolized efforts be made to obtain an early or at least the same hospital stay abdominal fascial closure [GRADE 1D]."

- "We suggest that biologic meshes should not be routinely used in the early closure of the open abdomen compared to alternative strategies [GRADE 2D]."

Montori et al. reported on a prospective case series of patients who had abdominal wall reconstruction using a dermal non-cross-linked swine collagen prostheses [87]. A total of 17 out of 30 were treated with open abdomen for various reasons. One mesh out of 17 was removed. Fascial closure was achieved in nine patients. The mesh was put in a sublay position in nine, intraperitoneally in five, in an onlay position in two and in an inlay position in one patient. Time to definitive closure was median 6 days. Four patients had a stoma. ICU stay was median 24 days, and the following ward stay was 28 days. A total of 10 of 17 patients (59\%) had some sort of complication; five patients died (two for aortic rupture, two for septic shock, one for respiratory insufficiency and septic shock), one mesh was removed due to a duodenal fistula with wound infection. Follow-up was completed at 3 (nine patients) and 6 (six patients) months; two recurrences were reported.

Burlew et al. reported on 100 consecutive patients that underwent damage control where 49 attained fascial closure at second laparotomy [88]. The remaining 51 required open abdomen and fascial closure could not be attained in 10 (20\%). Two patients had skin closure only. The remaining eight patients had an acellular human skin graft. Two patients had their mesh removed due to infection and a 
split-thickness skin graft was applied. No long-term results were reported.

Taixiera et al. reported on open abdomen in trauma patients [89]. A total of 93/900 (10\%) laparotomies were left open and 85 of these $93(91 \%)$ survived and fascial closure was achieved in 72 (85\%) between 1 and 21 days. Out of the remaining 13, seven were successfully closed using a biologic mesh, five by skin graft, and one by skin closure. No long-term data were available.

Sutton et al. reported on using a biosynthetic mesh $\left(\right.$ Gore Bio- $\mathrm{A}^{\circledR}$ ) in management of the open abdomen after operation for a strangulated perforated intrathoracic hiatal hernia [90]. Early closure was achieved using an onlay mesh after managing the septic situation. Defect size was not defined by the authors. The skin could be closed in all cases. A good cosmetic result and no hernia after 4 months were observed.

Caviggioli et al. reported on a patient with a complicated history of peritonitis. An enterocutaneous fistula was created due to enteric leakage [91]. A large defect of the abdominal wall was reconstructed using a porcine crosslinked mesh. Negative pressure wound therapy was applied on top of the mesh to promote formation of granulation tissue on top of the mesh. The mesh was used as a scaffold before a split-thickness skin graft was applied successfully on a small remaining central part. Wound healing was achieved after 55 days. No hernia was reported until 6 months.

Primary closure does not seem to be possible in around $10 \%$ of patients after open abdomen treatment. All together, 34 patients have been reported on having a definitive closure using a biologic or biosynthetic mesh. Wound infection rate was 24 and $11 \%$ of meshes were removed. Two (7.4\%) recurrences were reported at short time follow-up. Bridging was not reported on separately. The overall mortality in patients closed with a biologic mesh was $20 \%$, but probably not related to the mesh per se.

The literature does not give any evidence for or against the use of biologic or biosynthetic meshes for definitive closure of the open abdomen if bridging is avoided. A note of caution is that biologic meshes degrade over time and their use is not recommended when bridging is required or when an upper GI leakage is present.

Conclusion International guidelines do not recommend routine use of biologic or biosynthetic meshes in early closure of the open abdomen. Alternative strategies are recommended. Concerning short-term outcome, it seems safe to use either a biologic or biosynthetic or synthetic mesh, if fascial closure can be achieved. Negative wound pressure treatment can be recommended to reduce wound morbidity and shorten wound healing (LoE GRADE: very low).
Treatment of abdominal wall defects with enteric fistulas by the use of biologic or biosynthetic meshes

Patients with enteric fistulas and an abdominal wall defect present an extreme challenge to surgeons and have been associated with significant morbidity and mortality [92]. Key steps in managing patients with enterocutaneous fistulation and an abdominal wall defect include dealing effectively with abdominal sepsis and providing safe and effective nutritional support and skin care, then assessing intestinal and abdominal anatomy, before undertaking reconstructive surgery [93]. Incomplete sterility with contamination from enteric organisms implicates the more prominent role of biologic hernia implants and autologous reconstructive methods, such as component separation [94].

Connolly et al. [95] used inlay mesh (Permacol $n=12$, Vicryl $n=12$, Vypro $n=3$ ) when suture repair was not possible. Incisional hernia rates were expectedly high at 29 months of follow-up (42\% for Permacol, 92\% for Vicryl and $0 \%$ for Vypro), but also the refistulisation rate was extremely high ( $42 \%$ vs. $12 \%$ for Vicryl/Vypro; $p=n s$ ). All Permacol patients who developed a refistulisation had a recurrence later on.

Krpata et al. [96] described a group of 37 patients with fistula closure and abdominal wall reconstruction (mean defect area $426 \mathrm{~cm}^{2}$ ), using retrorectus or IPOM biologic non-cross-linked mesh. Mesh bridging was required in $11 \%$ of patients. Overall postoperative wound morbidity was $65 \%$. About one-third of these patients needed surgical debridement, without mesh explantation. Five patients developed an anastomotic leak/recurrent fistula; four of them had their mesh placed intraabdominally. With a mean follow-up of 20 months, $1 / 3$ of the patients developed a recurrence.

Conclusion In case of enterocutaneous fistula, the use of biologic mesh allows a one-stage repair, if possible without bridging, with acceptable outcomes. A high wound morbidity, risk for refistulisation, and recurrence rate have to be expected (LoE grade: very low).

\section{Component separation technique with biologic or biosynthetic mesh}

Abdominal wall reconstruction remains a challenging surgery. Difficulty obtaining primary fascial closure can compromise the success of the operation [97]. Techniques such as component separation have facilitated our ability to achieve primary fascial closure [97]. In patients with a moderate loss of abdominal domain, component separation may allow for primary midline fascial closure without the use of a mesh [97]. However, despite abdominal wall continuity, recurrence and bulging can remain an issue [97]. In an effort to minimize the risk of recurrence, the use 


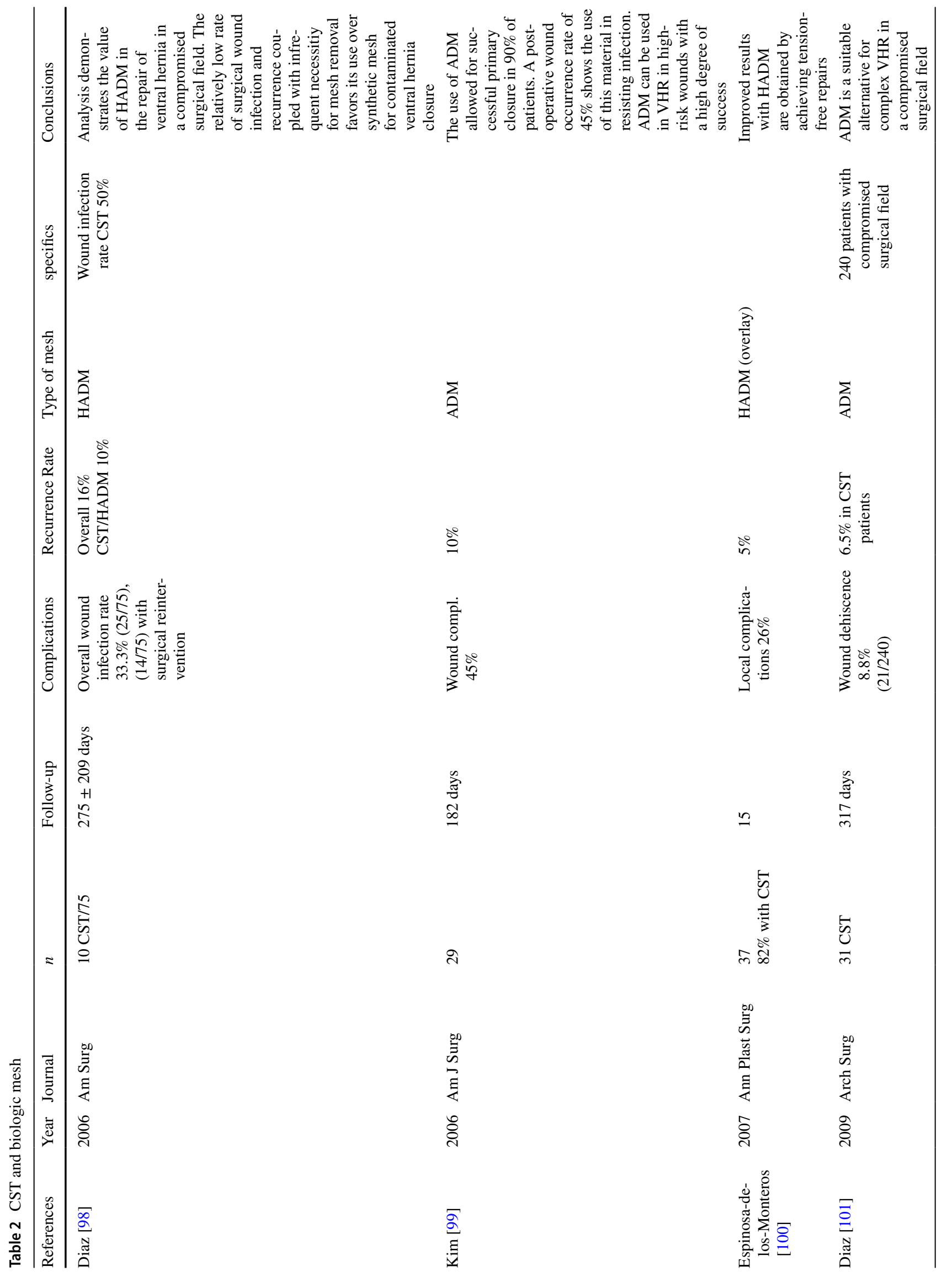




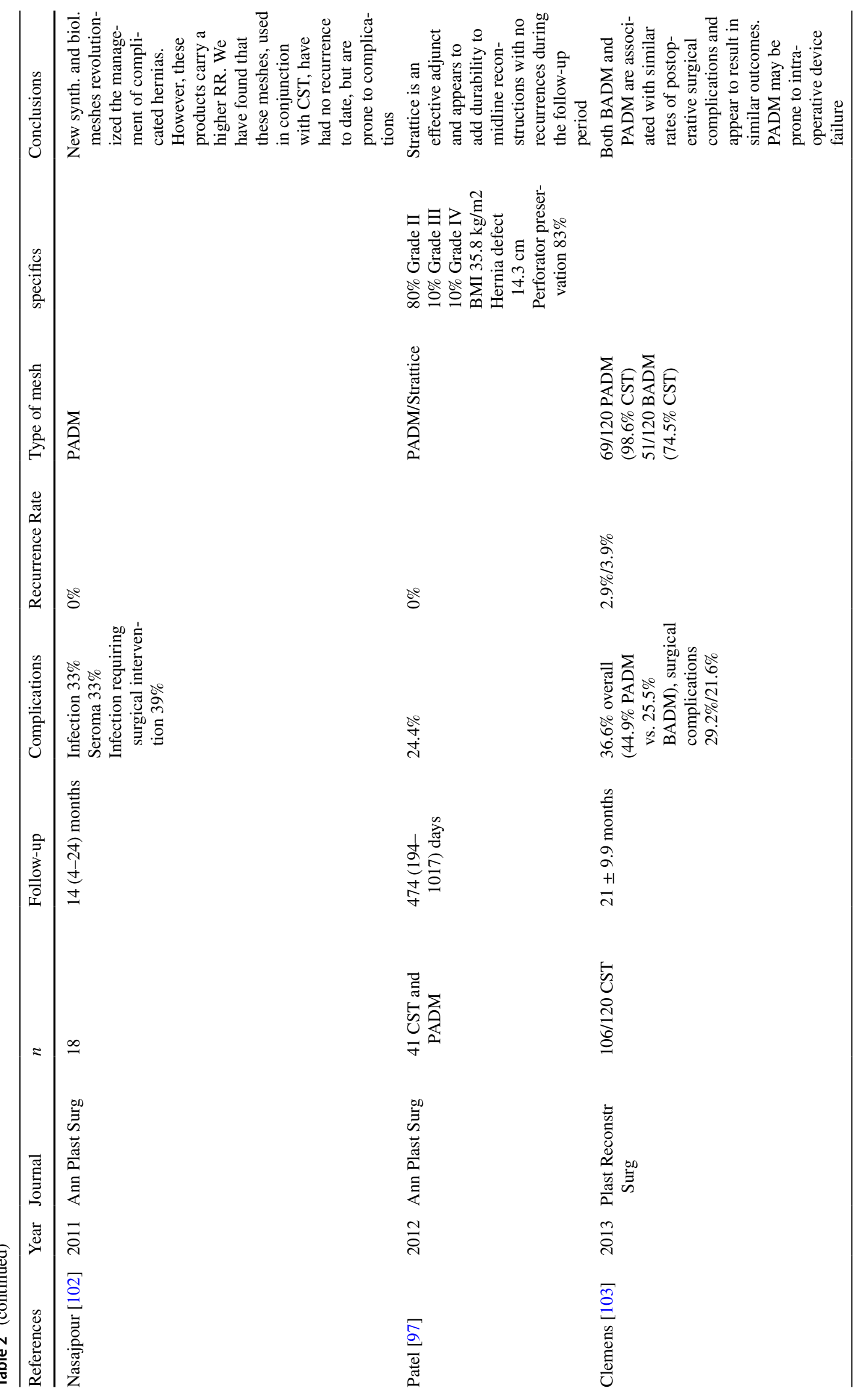




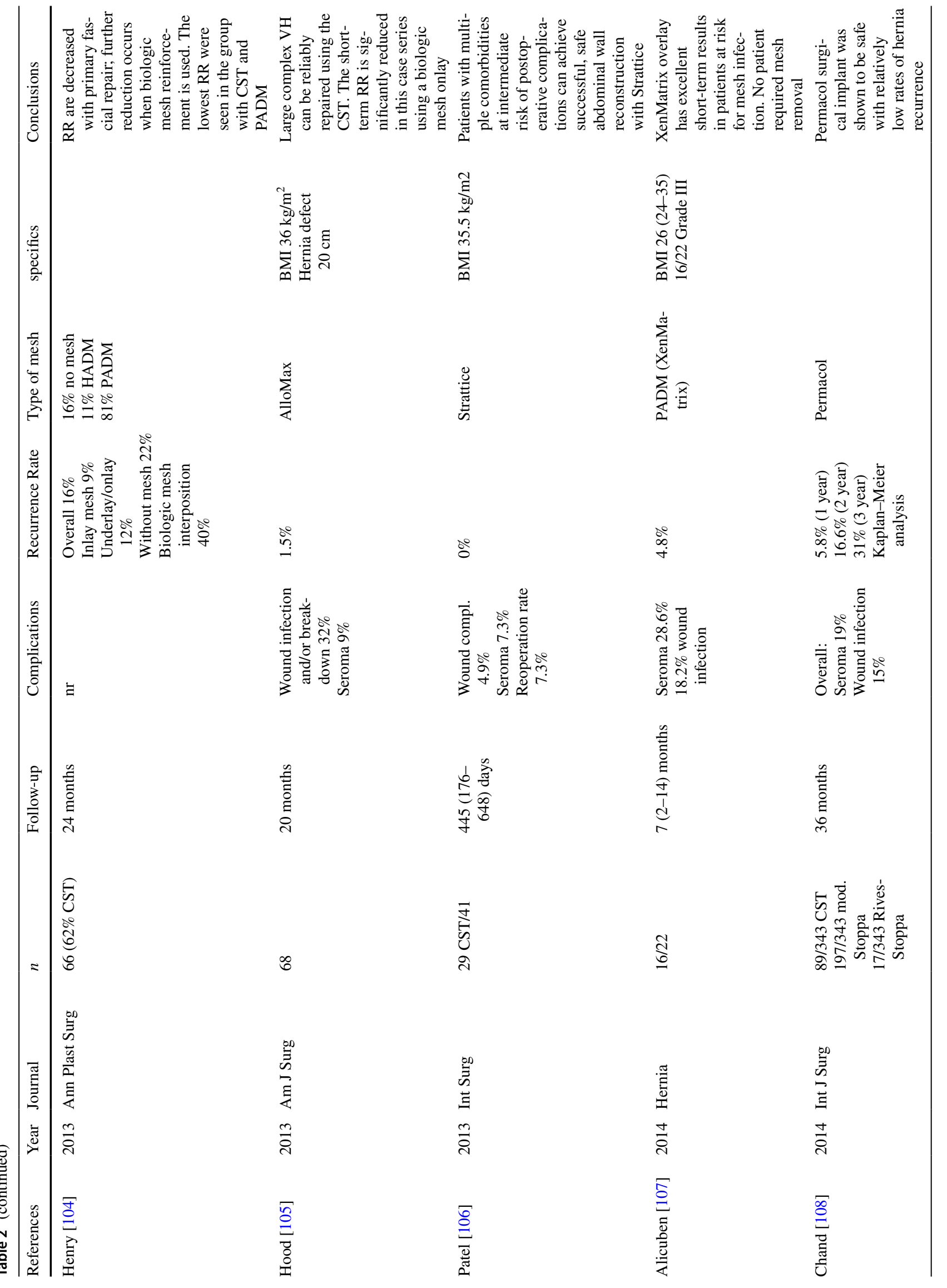




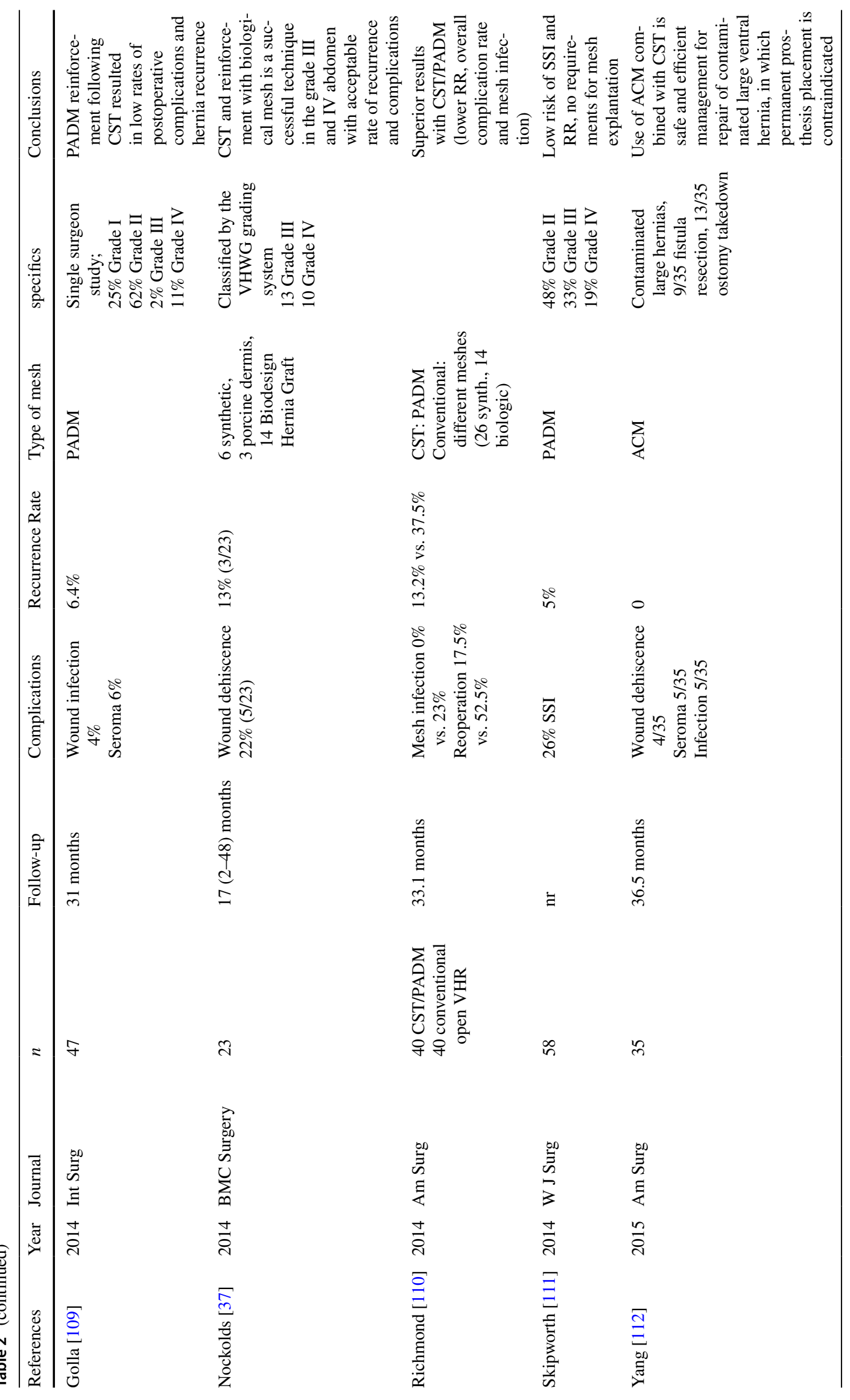




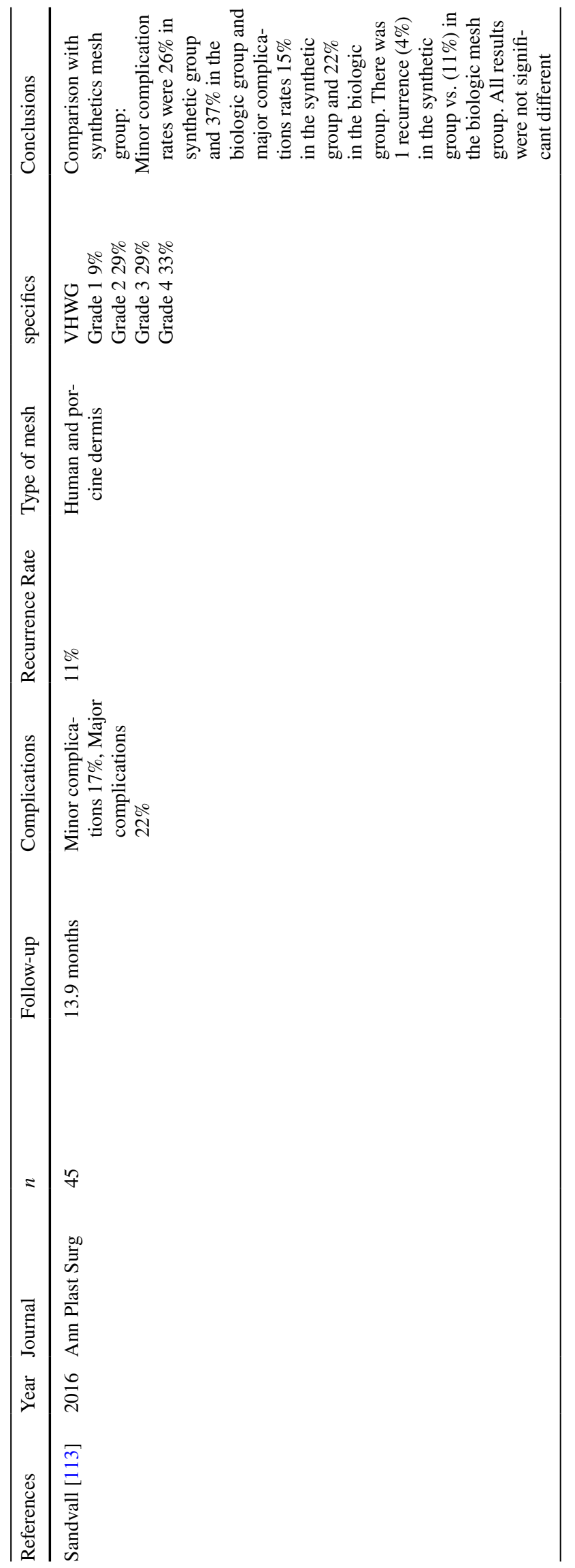




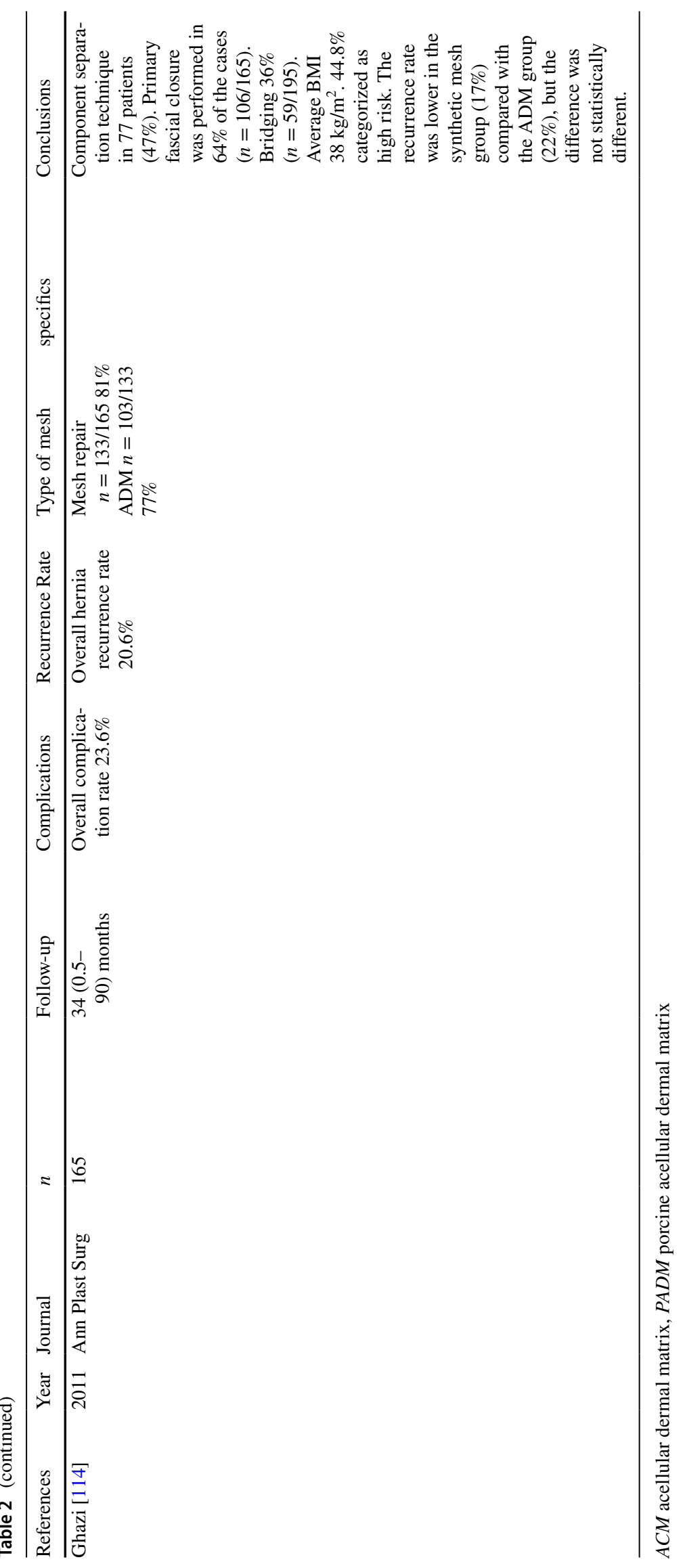


of synthetic mesh to reinforce the component separation has been advocated [97]. Despite the benefits of synthetic mesh, potential drawbacks remain [97]. In patients of high risk for complications, wound dehiscence and/or infection can lead to mesh infections and multiple secondary procedures, oftentimes leading to mesh removal [97]. Biologic meshes are associated with a high salvage rate when faced with infection [13].

To assess the role of biologic meshes for complex abdominal wall reconstructions with component separation, there are several studies, with studies with more or fewer than 40 patients being somewhat evenly balanced (Table 2) [37, 97-112]. Here, too, there is widespread variability in the follow-up times. Often, complication rates of up to $30 \%$ and more have been reported. The reported recurrence rates vary between 0 and $40 \%$, but most reports do not exceed $10-15 \%$. A common feature of the majority of studies is that they involve complex or very complex patient collectives with concomitant wound infection or wound contamination and/or patients with high BMI. All studies except two $[113,114]$ come without the comparison with synthetic meshes to the questionable conclusion that biologic meshes confer "advantages" for these patients undergoing complex abdominal wall reconstruction in combination with a component separation technique. However, certain studies have reported complications in relation to the meshes used $[102,103]$. The recurrence rate reported by the majority of studies-while taking account of the difficult baseline conditions-was "relatively low", the proportion of mesh explantations reported was low and in almost all studies was $0 \%$. These studies are all clinical observational studies with poorly controlled baseline and target conditions, although many studies endeavored to implement stratification with regard to wound contamination/infection. Overall, the study conditions were very heterogeneous, in particular in terms of the wound contamination grade, implantation techniques employed and, above all, the differences in the materials used. As such, any form of comparison of these studies is not meaningful.

Conclusion Component separation technique reinforced with biologic meshes has no significantly higher recurrence rate compared with synthetic meshes in clean field operations and patients with higher infection risks. However, the number of major SSO/SSI including need for reoperation does not seem to be decreased substantially by the use of biologic versus synthetic meshes. In the subgroup of patients with contaminated surgical field, there might be a place for the use of biologic mesh due to potentional higher salvage rate in case of mesh infection. Further high-quality comparative studies are needed (LoE GRADE: low).

\section{Summary}

Criticism is addressed in several review articles on the poor standard of studies concerning the use of biologic and biosynthetic meshes mainly consisting of retrospective case series without comparison with synthetic meshes. The critical review of the cumulative data regarding biologic and biosynthetic mesh use under contaminated conditions does not support the claim of better results than synthetic meshes. Biologic and biosynthetic mesh should not be used in a bridging situation. There seems to be no clear advantages of biologic and biosynthetic meshes in inguinal hernia repair. There is no evidence for the use of biologic or biosynthetic meshes in the prevention of incisional and parastomal hernias. In complex abdominal wall hernia repairs (incarcerated hernia, parastomal hernia, infected mesh, open abdomen, entero-cutaneous fistula, and component separation technique), biologic and biosynthetic meshes do not provide a superior alternative to synthetic meshes. Concluding these results of the literature review and consensus meeting biologic and biosynthetic meshes cannot be recommended for routine use. There is an urgent need for high standard comparative studies in well-defined patient populations.

\section{Compliance with ethical standards}

Conflict of interest NNA, SAA, FF, MMH, FKA, IK, FM, SKN, AP, WR, HS, and BS declare no conflict of interest. NS declares conflict of interest directly related to the submitted work. IRD, RHF, MM, AM, SM, FM, MS, CS, and GW declare conflict of interest not directly related to the submitted work. FK declares conflict of interest directly and not directly related to the submitted work.

Ethical approval This article does not contain any studies with human participants or animals performed by the authors.

Human and animal rights This article does not contain any study with animals performed by any of the authors.

Informed consent For this type of article informed consent is not required.

Open Access This article is distributed under the terms of the Creative Commons Attribution-NonCommercial 4.0 International License (http://creativecommons.org/licenses/by-nc/4.0/), which permits any noncommercial use, distribution, and reproduction in any medium, provided you give appropriate credit to the original author(s) and the source, provide a link to the Creative Commons license, and indicate if changes were made.

\section{References}

1. FitzGerald JF, Kumar AS (2014) Biologic versus synthetic mesh reinforcement: what are the pros and cons? Clin Colon Rectal Surg 27:140-148. https://doi.org/10.1055/s-0034-1394155 
2. Atema JJ, de Vries FEE, Boermeester MA (2016) Systematic review and meta-analysis of the repair of potentially contaminated and contaminated abdominal wall defects. Am J Surg 212:982-995. https://doi.org/10.1016/j.amjsurg.2016.05.003

3. Cross W, Kumar A, Kowdley GC (2014) Biological mesh in contaminated fields-overuse without data: a systematic review of their use in abdominal wall reconstruction. Am Surg 80:3-8

4. Huerta S, Varshney A, Patel PM, Mayo HG, Livingston EH (2016) Biological mesh implants for abdominal hernia repairUS food and drug adminstration approval process and systematic review of its efficacy. JAMA Surg. https://doi.org/10.1001/ jamasurg.215.5234

5. Hiles M, Ritchie RDR, Altizer AM (2009) Are biologic grafts effective for hernia repair? Surg Innov 16(1):26-37. https://doi. org/10.1177/1553350609331397

6. Peppas G, Gkegkes ID, Makris MC, Falagas ME (2010) Biological mesh in hernia repair, abdominal wall defects, and reconstruction and treatment of pelvic organ prolapse: a review of the clinical evidence. Am Surg 76:1290-1299

7. Smart NJ, Bloor S (2012) Durability of biologic implants for use in hernia repair: a review. Surg Innov 19:221. https://doi. org/10.1177/1553350611429027

8. Novitsky YW, Rosen MJ (2012) The biology of biologics: basic science and clinical concepts. Plast Reconstr Surg. https://doi. org/10.1097/prs.0b013e31825f395b

9. Smart NJ, Bryan N, Hunt A (2012) A scientific evidence for the efficacy of biologic implants for soft tissue reconstruction. Colorectal Dis 14(Suppl. 3):1-6. https://doi.org/10.1111/ codi. 12042

10. Kissane NA, Itani KMF (2012) A decade of ventral incisional hernia repairs with biologic acellular dermal matrix: what have we learned? Plast Reconstr Surg. https://doi.org/10.1097/ prs.0b013e318265a5ec

11. Beale EW, Hoxworth RE, Livingston EH, Trussler AP (2012) The role of biologic mesh in abdominal wall reconstruction: a systematic review of the current literature. Am J Surg 204:510 517. https://doi.org/10.1016/j.amjsurg.2012.03.009

12. Smart NJ, Marshall M, Daniels IR (2012) Biological meshes: a review of their use in abdominal wall hernia repairs. Surgeon 10:159-171. https://doi.org/10.1016/j.surge.2012.02.006

13. Slater NJ, van der Kolk M, Hendriks T, van Goor H, Bleichrodt RP (2012) Biologic grafts for ventral hernia repair: a systematic review. Am J Surg. https://doi.org/10.1016/j.amjsu rg.2012.05.028

14. Balayssac D, Poinas AC, Pereira B, Pezet D (2013) Use of permacol in parietal and general surgery: a bibliographic review. Surg Innov 20:176. https://doi.org/10.1177/1553350612447690

15. Godden AR, Daniels IR, Giordano P (2012) The role of biologic meshes in abdominal wall reconstruction. Colorectal Dis 14(Suppl. 3):7-11. https://doi.org/10.1111/codi.12043

16. Ferzoco SJ (2013) A systematic review of outcomes following repair of complex ventral incisional hernias with biologic mesh. Int Surg 98:399-408. https://doi.org/10.9738/intsurg-d-12-00002 .1

17. Bellows CF, Smith A, Malsbury J, Helton WC (2013) Repair of incisional hernias with biological prosthesis: a systematic review of current evidence. Am J Surg 205:85-101. https://doi. org/10.1016/j.amjsurg.2012.02.019

18. Primus FE, Harris HW (2013) A critical review of biologic mesh use in ventral hernia repairs under contaminated conditions. Hernia 17(1):21-30. https://doi.org/10.1007/s10029-012-1037-8

19. Broyles JM, Abt NB, Sacks JM, Butler CE (2014) Bioprosthetic tissue matrices in complex abdominal wall reconstruction. Plast
Reconstr Surg Glob Open 1(9):e91. https://doi.org/10.1097/ gox.0000000000000036

20. King KS, Albino FP, Bhanot P (2014) Biologic mesh for abdominal wall reconstruction. Chronic Wound Care Manag Res 1:57-65

21. Smart NJ, Bryan N, Hunt JA, Daniels IR (2014) Porcine dermis implants in soft-tissue reconstruction: current status. Biologics 8:83-90. https://doi.org/10.2147/btt.s46469

22. Montgomery A (2013) The battle between biological and synthetic meshes in ventral hernia repair. Hernia 17:3-11. https:// doi.org/10.1007/s10029-0131043-5

23. Baker A, Young K, Potter J, Madan I (2010) A review of grading systems for evidence-based guidelines producted by medical specialties. Clin Med 10(4):358-363

24. Shankaran V, Weber DJ, Reed L, Luchette FA (2011) A review of available prosthetics for ventral hernia repair. Ann Surg 253:16. https://doi.org/10.1097/SLA0b013e318f9b6e6

25. Scott JR, Deeken CR, Martindale RG, Rosen MJ (2016) Evaluation for a fully absorbable poly-hydroxybutyrate/absorbable barrier composite mesh in a procine model of vental hernia repair. Surg Endosc 30:3691-3701. https://doi.org/10.1007/s0046 4-016-5057-9

26. Deeken CR, Matthews BD (2013) Characterization of the mechanical strength, resorption properties, and histologic characteristics of a fully absorbable material (poly-4-hydroxybutyratePhasix mesh) in a porcine model of hernia repair. ISRN Surg. https://doi.org/10.1155/2013/238067

27. Hunter JD III, Cannon JA (2014) Biomaterials: so many choices, so little time. what are the differences? Clin Colon Rectal Surg 27:134-139. https://doi.org/10.1055/s-0034-1394087

28. Choi JJ, Palaniappa NC, Dallas KB, Rudich TB, Colon MJ, Divino CM (2012) Use of mesh during ventral hernia repair in clean-contaminated and dontaminated cases. Ann Surg 255:176180. https://doi.org/10.1097/SLA.0b013e31822518e6

29. Lee L, Mata J, Landry T, Khwaja KA, Vassiliou MC, Fried GM, Feldman LS (2014) A systematic review of synthetic and biologic materials for abdominal wall reinforcement in contaminated fields. Surg Endosc 28:2531-2546. https://doi.org/10.1007/s0046 4-014-3499-5

30. Darehzereshki A, Goldgarb M, Zehetner J, Moazzez A, Lipham JC, Mason RJ, Katkhouda N (2014) Biologic versus nonbiologic mesh in ventral hernia repair: a systematic review and metaanalysis. World J Surg 38:40-50. https://doi.org/10.1007/s0026 8-013-2232-1

31. Bondre IL, Holihan JL, Askenasy EP, Greenberg JA, Keith JN, Martindale RG, Roth JS, Liang MK (2016) Suture, synthetic, or biologic in contaminated ventral hernia repair. J Surg Res 200:488-494. https://doi.org/10.1016/j.jss.2015.09.007

32. Liang MK, Berger RL, Nguyen MT, Hicks SC, Li LT, Leong M (2014) Outcomes with porcine acellular dermal matrix versus synthetic mesh and suture in complicated open ventral hernia repair. Surg Infect (Larchmt) 15(5):506-512. https://doi. org/10.1089/sur.2013.090

33. Chamieh J, Tan WH, Ramirez R, Nohra E, Apakame C, Symons W (2016) Synthetic versus biologic mesh in single-stage repair of complex abdominal wall defects in a contraminated field. Surg Infect (Larchmt) 18(2):112-118

34. Majumder A, Winder JS, Wen Y, Pauli EM, Belyansky I, Novtsky YW (2016) Comparative analysis of biologic versus synthetic mesh outcomes in contaminated hernia repairs. Surgery 160:828-838. https://doi.org/10.1016/j.surg.2016.04.041

35. Ko JH, Wang EC, Salvay DM, Paul BC, Dumanian GA (2009) Abdoiminal wall reconstruction. Arch Surg 144(11):1047-1055

36. El-Gazzaz G, Erem HH, Aytac E, Salcedo L, Stocchi L, Kiran RP (2013) Risk of infection and hernia recurrence for patients 
undergoing ventral hernia repair with non-absorbable or biological mesh during open bowel procedures. Tech Coloproctol 17:315-320. https://doi.org/10.1007/s10151-012-0928-0

37. Nockolds CL, Hodde JP, Rooney PS (2014) Abdominal wall reconstruction with components separation and mesh reinforcement in complex hernia repair. BMC Surg 14:25. https://doi. org/10.1186/1471-2482-14-25

38. Gurrado A, Franco IF, Lissidini G, Greco G, De Fazio M, Pasculli A, Girardi A, Piccinni G, Memeo V, Testini M (2015) Impact of pericardium bovine patch $\left(\right.$ Tutomesh $^{\circledR}$ ) on incisional hernia treatment in contaminated or potentially contaminated fields: retrospective comparative study. Hernia 19:259-266. https ://doi.org/10.1007/s10029-014-1228-6

39. Sahoo S, Haskins IN, Huang LC, Krpata DM, Derwin KA, Poulose BK, Rosen MJ (2017) Early wound morbidity after open ventral hernia repair with biosynthetic or polypropylene mesh. J Am Coll Surg. https://doi.org/10.1016/j.jamcollsur g.2017.07.1067

40. Madani A, Niculiseanu P, Marini W, Kaneva PA, Mappin-Kasirer B, Vassiliou MC, Khwaja K, Fata P, Fried GM, Feldman LS (2016) Biologic mesh for repair of ventral hernias in contraminated fields: long-term clinical and patient-reported outcomes. Surg Endosc. https://doi.org/10.1007/s00464-016-5044-1

41. Sbitany H, Kwon E, Chern H, Finlayson E, Varma MG, Hansen SL (2015) Outcomes analysis of biologic mesh use for abdominal wall reconstruction in clean-contaminated and contaminated ventral hernia repair. Ann Plast Surg 75:201-204. https://doi. org/10.1097/SAP.0000000000000030

42. Latifi R, Samson D, Haider A, Azim A, Iftikhar H, Joseph B, Tilley E, Con J, Gashi S, El-Menyar A (2017) Risk-adjusted adverse outcomes in complex abdominal wall hernia repair with biologic mesh: a case series of 140 patients. Int J Surg 43:26-32

43. Atema JJ, Furnée EJ, Maeda Y, Warusavtarne J, Tanis PJ, Bemelman WA, Vaizey CJ (2017) Major complex abdominal wall repair in contraminated fields with use of a non-cross-linked biologic mesh: a dual-institutional experience. World J Surg. https://doi. org/10.1007/s00268-017-3962-2

44. Buell JF, Sigmon D, Ducon C, Shapiro M, Teja N, Wynter E, Hanisee MK, Parker G, Kandil E, Darden M (2017) Intitial experience with biologic polymer scaffold (poly-4-hydroxybuturate) in complex abdominal wall reconstruktion. Ann Surg 266:185188. https://doi.org/10.1097/SLA.0000000000001916

45. Rosen MJ, Bauer JJ, Harmaty M, Carbonell AM, Cobb WS, Matthews B, Goldblatt MI, Selzer DJ, Poulose BJ, Hansson BME, Rosman C, Chao JJ, Jacobsen GR (2017) Multicenter prospective, longitudinal study of the recurrence, surgical site infection, and quality of life after contaminated ventral hernia repair using biosynthetic absorbable mesh. Ann Surg 265:205-211. https:// doi.org/10.1097/SLA.0000000000001601

46. Liang MK, Holihan JL, Itani K, Alawadi ZM, Gonzalez JRF, Askenasy EP, Ballecer C, Chong HS, Goldblatt MI, Greenberg JA, Harvin JA, Keith JN, Martindale RG, Orenstein S, Richmond B, Roth JS, Szotek P, Towfigh S, Tsuda S, Vaziri K, Berger DH (2017) Ventral hernia management. Ann Surg 265:80-89. https ://doi.org/10.1097/sla.0000000000001701

47. Albino FP, Patel KM, Nahabedian MY, Sosin M, Attinger CF, Bhanot P (2013) Does mesh location matter in abdominal wall reconstruction? a systematic review of the literature and a summary of recommendations. Plast Reconstr Surg 132(5):12951304. https://doi.org/10.1097/prs.0b013e3182a4c393

48. Holihan JL, Nguyen DH, Nguyen MT, Mo J, Kao LS, Liang MK (2016) Mesh location in open ventral hernia repair: a systematic review and network meta-analysis. World J Surg 40(1):89-99. https://doi.org/10.1007/s00268-015-3252-9

49. Miserez M, Grass G, Weiss C, Stützer H, Sauerland S (2010) Closure of the LAPSIS trial. Br J Surg 97:1598
50. Basta MN, Fischer JP, Kovach SL (2015) Assessing complications and cost-utilization in ventral hernia repair utilizing biologic mesh in a bridged underlay technique. Am J Surg 209(4):695-702. https://doi.org/10.1016/j.amjsurg.2014.04.017

51. Giordano S, Garvey PB, Baumann DP, Liu J, Butler CE (2016) Primary fascial closure with biologic mesh reinforcement results in lesser complication and recurrence rates than bridged biologic mesh repair for abdominal wall reconstruction: a propensity score analysis. Surgery. https://doi.org/10.1016/j.surg.2016.08.009

52. Simons MP, Aufenacker T, Bay-Nielsen M, Bouillot JL, Campanelli G, Conze J, de Lange D, Fortelny R, Heikkinen T, Kingsnorth A, Kukleta J, Morales-Conde S, Nordin P, Schumpelick V, Smedberg S, Smietanski M, Weber G, Miserez M (2009) European Hernia Society guidelines on the treatment of inguinal hernia in adult patients. Hernia 13:343-403. https://doi.org/10.1007/ s10029-009-0529-7

53. Miserez M, Peeters E, Aufenacker T, Bouillot JL, Campanelli G, Conze J, Fortelny R, Heikkinen T, Jorgensen LN, Kukleta J, Morales-Conde S, Nordin P, Schumpelick V, Smedberg S, Smitanski M, Weber G, Simons MP (2014) Update with level 1 studies of the European Hernia Society guidelines on the treatment of inguinal hernia in adult patients. Hernia 18:151-163. https:// doi.org/10.1007/s10029-014-1236-6

54. Bittner R, Arregui ME, Bisgaard T, Dudai M, Ferzli GS, Fitzgibbons RJ, Fortelny RH, Klinge U, Köckerling F, Kuhry E, Kukleta J, Lomanto D, Misra MC, Montgomery A, Morales-Conde S, Reinpold W, Rosenberg J, Sauerland S, Schug-Pass C, Singh K, Timoney M, Weyhe D, Chowbey P (2011) Guidelines for laparoscopic (TAPP) and endoscopic (TEP) treatment of inguinal hernia [International Endohernia Society (IEHS)]. Surg Endosc 25:2773-2843. https://doi.org/10.1007/s00464-011-1799-6

55. Bittner R, Montgomery MA, Arregui E, Bansal V, Bingener J, Bisgaard T, Buhck H, Dudai M, Ferzli GS, Fitzgibbons RJ, Fortelny RH, Grimes KL, Klinge U, Köckerling F, Kumar S, Kukleta J, Lomanto D, Misra MC, Morales-Conde S, Reinpold W, Rosenberg J, Singh K, Timoney M, Weyhe D, Chowbey P (2015) Update of guidelines on laparoscopic (TAPP) and endoscopic (TEP) treatment of inguinal hernia (International Endohernia Society). Surg Endosc 29:289-321. https://doi.org/10.1007/ s00464-014-3917-8

56. Poelman MM, van den Heuvel B, Deelder JD, Abis GSA, Beudeker N, Bittner R, Campanelli G, van Dam D, Dwars BJ, Eker HH, Fingerhut A, Khatkov I, Kockerling F, Kukleta JF, Miserez M, Montgomery A, Munoz Brands RM, Morales-Conde S, Muysoms FE, Soltes M, Tromp W, Yavuz Y, Bonjer HJ (2013) EAES consensus development conference on endoscopic repair of groin hernias. Surg Endosc 27:3505-3519. https://doi. org/10.1007/s00464-013-3001-9

57. Köckerling F, Alam NN, Narang SK, Daniels IR, Smart NJ (2015) Biological meshes for inguinal hernia repair-review of the literature Front. Surg 2:48. https://doi.org/10.3389/fsurg .2015 .00048

58. Nie X, Xiao D, Wang W, Song Z, Yang Z, Chen Y, Gu Y (2015) Comparison of porcine small intestinal submucosa versus polypropylene in open inguinal hernia repair: a systematic review and meta-analysis. PLoS ONE. https://doi.org/10.1371/journ al.pone. 0135073

59. Fang Z, Ren F, Zhou J, Tian J (2015) Biologic mesh versus synthetic mesh in open inguinal hernia repair: system review and meta-analysis. ANZ J Surg 85:910-916. https://doi.org/10.1111/ ans. 13234

60. Öberg S, Andresen K, Rosenberg J (2017) Absorbable meshes in inguinal hernia surgery: a systematic review and meta-analysis. Surg Innov 24:289-298. https://doi.org/10.1177/1553350617 697849 
61. Timmermans L, de Goede B, Eker HH, van Kempen BJ, Jeekel J, Lange JF (2013) Meta-analysis of primary mesh augmentation as prophylactic measure to prevent incisional hernia. Dig Surg 30:401-409. https://doi.org/10.1159/000355956

62. Jairam AP, Timmermans L, Eker HH, Pierik GEGJM, van Klaveren D, Steyerberg EW, Timmann R, van der Ham AC, Dawson I, Charbon JA, Schumacher C, Mihaljevic A, Izbicki JR, Fikatas P, Knebel P, Fortelny RH, Kleinrensink GJ, Lange JF, Jeekel HJ, PRIMA Trialist Group (2017) Prevention of incisional hernia with prophylactic onlay and sublay mesh reinforcement versus primary suture only in midline laparotomies (PRIMA): 2-year follow-up of a multicenter, double-blind, randomized controlled trial. Lancet. https://doi.org/10.1016/s0140 $-6736(17) 31332-6$

63. Timmermans L, Eker HH, Steyerberg EW, Jairam A, de Jong D, Pierik EG, Lases SS, van der Ham AC, Dawson I, Charbon J, Schumacher C, Izbicki JR, Neuhaus P, Knebel P, Fortelny R, Kleinrensink GJ, Jeekel J, Lange JF (2017) Short-term results of a randomized controlled trial comparing primary suture with primary glued mesh augmentation to prevent incisional hernia. Ann Surg 261(2):276-281. https://doi.org/10.1097/sla.00000 00000000798

64. Muysoms FE, Antoniou SA, Bury K, Campanelli G, Conze J, Cuddurullo D, de Beaux AC, Deerenberg EB, Est B, Fortelny RH, Gillion JF, Henriksen NA, Israelsson L, Jairam A, Jänes A, Jeekel J, López-Cano M, Miserez M, Morales-Conde S, Sanders DL, Simons MP, Smietanski M, Venclauskas L, Berrevoet F (2015) European Hernia Society guidelines on the closure of abdominal wall incisions. Hernia 19:1-24. https://doi. org/10.1007/s10029-014-1342-5

65. Muysoms FE, Jairam A, López-Cano M, Śmietański M, Woeste G, Kyle-Leinhase I, Antouniou SA, Köckerling F, BioMesh Study Group (2016) Prevention of incisional hernias with biological mesh: a systematic review of the literature. Front Surg 3:53. https://doi.org/10.3389/fsurg.2016.00053

66. Cross AJ, Buchwald PL, Frizelle FA, Eglinton TW (2016) Metaanalysis of prophylactic mesh to prevent parastomal hernia. BJS. https://doi.org/10.1002/bjs.10402

67. López-Cano Brandsma HT, Bury K, Hansson B, Kyle-Leinhase I, Alamino JG, Muysoms F (2017) Prophylactic mesh to prevent parastomal hernia after end colostomy: a meta-analysis and trial sequential analysis. Hernia 21(2):177-189. https://doi. org/10.1007/s10029-016-1563-X

68. Zhu JJ, Pu YW, Yang XD, Zhang DB, Zhao K, Peng W, Xing CG (2016) Prophylactic mesh application during colostomy to prevent parastoma hernia: a meta-analysis. Gastroenterol Res Pract 216:10. https://doi.org/10.1155/2016/1694265

69. Partel SV, Zhang L, Chadi SA, Wexner SD (2017) Prophylactic mesh to prevent parastomal hernia: a meta-analysis of randomized controlled studies. Tech Coloproctol 21(1):5-13. https:// doi.org/10.1007/s1051-016-1559-7

70. Fortelny RH, Hofmann A, May C, Köckerling F, BioMesh Study Group (2015) Prevention of a parastomal hernia by biological mesh reinforcement. Front Surg 2:53. https://doi.org/10.3389/ sfurg.2015.00053

71. Slater NJ, Montgomery A, Berrevoet F, Carbonell AM, Chang A, Franklin M, Kercher KW, Lammers BJ, Parra-Davilla E, Roll S, Towfigh S, van Geffen E, Conze J, van Goor H (2014) Criteria for definition of a complex abdominal wall hernia. Hernia 18:7-17. https://doi.org/10.1007/s10029-013-1168-6

72. HerniaSurge Goup (2018) International guidelines for Groin Hernia management. Hernia. https://doi.org/10.1007/s1002 9-017-1668-x

73. Fortelny RH, Hofmann A, May C, Köckerling F (2016) Open and laparoendoscopic repair of incarcerated abdominal wall hernias by the use of biological and biosynthetic meshes. Front Surg 3:10. https://doi.org/10.3389/fsurg.2016.00010

74. Birindelli A, Sartelli M, Di Saverio S et al (2017) WSES guidelines for emergency repair of complicated abdominal wall hernias. World J Emerg Surg 12:37. https://doi.org/10.1186/s1301 7-017-0149-y

75. Bittner R, Bingener-Casey J, Dietz U, Fabian M, Ferzli GS, Fortelny RH, Köckerling F, Kukleta J, LeBlanc K, Lomanto D, Misra MC, Bansal VK, Morales-Conde S, Ramshaw B, Reinpold W, Rim S, Rohr M, Schrittwieser R, Simon T, Smietanski B, Stechemesser B, Timoney M, Chowbey P (2014) Guidelines for laparoscopic treatment of ventral and incisional abdominal wall hernias (International Endohernia Society [IEHS])—part 1. Surg Endosc 28:2-29. https://doi.org/10.1007/s00464-013-3170-6

76. Bittner R, Bingener-Casey J, Dietz U, Fabian M, Ferzli GS, Fortelny RH, Köckerling F, Kukleta J, LeBlanc K, Lomanto D, Misra MC, Morales-Conde S, Ramshaw B, Reinpold W, Rim W, Rohr M, Schrittwieser R, Simon T, Smietanski M, Stechemesser B, Timoney M, Chowbey P (2014) Guidelines for laparoscopic treatment of ventral and incisional abdominal wall hernias International Endohernia Society [IEHS]) - part 2. Surg Endosc 28:353-379. https://doi.org/10.1007/s00464-013-3171-5

77. Bittner R, Bingener-Casey J, Dietz U, Fabian G, Fortelny RH, Köckerling F, Kukleta J, LeBlanc K, Lomanto D, Misra M, Morales-Conde S, Ramshaw B, Reinpold W, Rim S, Rohr M, Schrittwieser R, Simon T, Smietanski M, Stechemesser B, Timoney M, Chowbey P (2014) Guidelines for laparoscopic treatment of ventral and incisional abdominal wall hernias (International Endohernia Society [IEHS]) part III. Surg Endosc 28:380-404. https://doi.org/10.1007/s00464-013-3172-4

78. Hansson BM, Slater NJ, van der Velden AS, Groenewoud HM, Buyne OR, de Hingh IH, Bleichrodt RP (2012) Surgical techniques for parastomal hernia repair: a systematic review of the literature. Ann Surg 255(14):685-695. https://doi.org/10.1097/ sla.0b013e31824b44b1

79. DeAsis FJ, LapinB Gitelis ME, Ujiki MB (2015) Current state of laparoscopic parastomal hernia repair: A meta-analysis. World J Gastroenterol 21(28):8670-8677. https://doi.org/10.3748/wjg. v21.i28.8670

80. Shakarchi AI, Williams JG (2014) Systematic review of open techniques for parastomal hernia repair. Tech Coloproctol 18(5):427-432. https://doi.org/10.1007/s10151-013-1110-z

81. Slater NJ, Hansson BME, Buyne OR, Hendriks T, Bleichrodt RP (2011) Repair of parastomal hernias with biologic grafts: a systematic review. J Gastrointest Surg 15:1252-1258. https://doi. org/10.1007/s11605-011-1435-8

82. Montgomery A, Kallinowski F, Köckerling F (2016) Evidence for replacement of an infected synthetic by a biological mesh in abdominal wall hernia repair. Front Surg 2:67. https://doi. org/10.3389/fsurg2015.00067

83. Shubinets V, Carney MJ, Colen DL, Mirzabeigi MN, Weissler JM, Lanni MA, Braslow BM, Fisher JP, Kovach SJ (2017) Management of infected mesh after abdominal hernia repair. Ann Plast Surg. https://doi.org/10.1097/sap.0000000000001189

84. Chen Y, Ye J, Song W, Chen J, Yuan Y, Ren J (2014) Comparison of outcomes between early fascial closure and delayed abdominal closure in patients with open abdomen: a systematic review and meta-analysis. Gastroenterol Res Pract. https://doi. org/10.1155/2014.784056

85. Coccolini F, Biffi W, Catena F, Ceresoli M, Chiara O, Cimbanassi S, Fattori L, Leppaniemi A, Manfredi R, Montori G, Pesenti G, Sugrue M (2015) The open abdomen, indications, management and definitive closure. World J Emerg Surg 10:32. https://doi. org/10.1186/s13017-015-0026-5

86. Kirkpatrick AW, Roberts DJ, Jaeschke R, De Waele JJ, De Keulenaer BL, Duchesne J, Bjorck M, Leppäniemi A, Ejike JC, Sugrue 
M, Cheatham ML, Ivatury R, Ball CG, Reintam Blaser A, Regli A, Balogh Z, D_Amours S, De Laet I, Malbrain ML (2015) Methodological background and strategy for the 2012-2013 updated consensus definitations and clinical practice guidelines from the abdominal compartment society. Anaesthesiol Intensive Ther 47:s63-s77. https://doi.org/10.5603/ait.a2015.0081

87. Montori G, Coccolini F, Manfredi R, Ceresoli M, Campanati L, Magnone S, Pisano M, Poiasina E, Nita G, Catene F, Ansaloni L (2015) One year experience of swine dermal non-crosslinked collagen prostheses for abdominal wall repairs in elective and emergency surgery. World J Emerg Surg 10:28. https://doi. org/10.1186/s13017-015-0023-8

88. Burlew CC, Moore EE, Biffi WL, Bensard DD, Johnson JL, Barnett CC (2012) One hundred percent fascial approximation can be achieved in the postinjury open abdomen with a sequential closure protocol. J Trauma Acute Care Surg 72(1):235-241. https ://doi.org/10.1097/ta.0b013e318236b319

89. Teixeira PG, Salim A, Inaba K, Brown C, Browder T, Marqulies D, Demetriades D (2008) A prospective look at the current state of open abdomens. Am Surg 74(10):891-897

90. Sutton PA, Evans JP, Uzair S, Varghese JV (2013) The use of Gore Bio-A in the management of the open abdomen. BMJ Case Rep. https://doi.org/10.1136/bcr-2012-008064

91. Caviggioli F, Klinger FM, Lisa A, Maione L, Forcellini D, Vinci V, Codolini L, Klinger M (2014) Matching biological mesh and negative pressure wound therapy in reconstructing an open abdomen defect. Case Rep Med 2014:235930. https://doi. org/10.1155/2014/235930

92. Slater NJ, Bokkerink WJ, Konijn V, Bleichrodt RP, van Goor H (2015) Safety and durability of one-stage repair of abdominal wall defects with enteric fistulas. Ann Surg 261(3):553-557. https://doi.org/10.1097/sla.0000000000000733

93. Slade DA, Carlson GL (2013) Takedown of enterocutaneous fistula and complex abdominal wall reconstruction. Surg Clin N Am 93(5):1163-1183. https://doi.org/10.1016/j.surc.2013.06.006

94. Scheuerlein H, Settmacher U, Lenschow M, Rauchfuss F (2016) Complex incisional hernias. Arch Clin Gastroenterol 2(1):017026. https://doi.org/10.17352/2455-2283-000014

95. Connolly PT, Teubner A, Lees NP, Anderson ID, Scott NA, Carlson GL (2008) Outcome of reconstructive surgery for intestinal fistula in the open abdomen. Ann Surg 247(3):440-444. https:// doi.org/10.1097/sla.0b013e3181612c99

96. Krpata DM, Stein SL, Eston M, Ermlich B, Blatnik JA, Novitsky YW, Rosen MJ (2013) Outcomes of simultaneous large complex abdominal wall reconstruction and enterocutaneous fistula takedown. Am J Surg 205(3):354-358. https://doi.org/10.1016/j. amjsurg.2012.10.013 (discussion 358-359)

97. Patel KM, Nahabedian MY, Gatti M, Bhanot P (2012) Indications and outcomes following complex abdominal reconstruction with component separation combined with porcine acellular dermal matrix reinforcement. Ann Plast Surg 69:394-398. https://doi. org/10.1097/sap.0b013e31822f997b

98. Diaz JJ, Guy J, Berkes MB, Guilamondegui O, Miller RS (2006) Acellular dermal allograft for ventral hernia repair in the compromised surgical field. Am Surg 72(12):1181-1187 (discussion 1187-1188)

99. Kim H, Bruen K, Vargo D (2006) Acellular dermal matrix in the management of high-risk abdominal wall defects. Am J Surg 192:705-709. https://doi.org/10.1016/j.amjsurg.2006.09.003

100. Espinosa-de-los-Monteros A, de la Torre JI, Marrero I, Andrades P, Davis MR, Vásconez LO (2007) Utilization of human cadaveric acellular dermis for abdominal hernia reconstruction. Ann Plast Surg 58:264-267. https://doi.org/10.10978/01.sap.00002 54410.91132.a8
101. Diaz JJ Jr, Conquest AM, Ferzoco SJ, Vargo D, Miller P, Wu YC, Donahue R (2009) Multi-institutional experience using human acellular dermal matrix for ventral hernia repair in a compromised surgical field. Arch Surg 144(3):209-215

102. Nasajpour H, LeBlanc KA, Steele MH (2011) Complex hernia repair using component separation technique paired with intraperitoneal acellular porcine dermis and synthetic mesh overlay. Ann Plast Surg 66:280-284. https://doi.org/10.1097/SAP.0b013 e3181e9449d

103. Clemens MW, Selber JC, Liu J, Adelman DM, Baumann DP, Garvey PB, Butler CE (2013) Bovine versus porcine acellular dermal matrix for complex abdominal wall reconstruction. Plast Reconstr Surg 131:71. https://doi.org/10.1097/PRS.0b013e3182 $729 \mathrm{e} 58$

104. Henry CR, Bradburn E, Moyer KE (2013) Complex abdominal wall reconstrction. Ann Plast Surg 71:266-268. https://doi. org/10.1097/SAP.0b013e31828a49f9

105. Hood K, Millikan K, Pittman T, Zelhart M, Secemsky B, Rajan M, Myers J, Luu M (2013) Abdominal wall reconstruction: a case series of ventral hernia repair using the component separation technique with biologic mesh. Am J Surg 205:322-328. https:// doi.org/10.1016/j.amjsurg.2012.10.024

106. Patel KM, Albino FP, Nahabedian Y, Bhanot P (2013) Critical analysis of strattice performance in complex abdominal wall reconstruction: intermediate-risk patients and early complications. Int Surg 98:379-384. https://doi.org/10.9738/intsurg-d-1300053-1

107. Alicuben ET, Demeester SR (2014) Onlay ventral hernia repairs using porcine non-cross-linked dermal biologic mesh. Hernia 18:705-712. https://doi.org/10.1007/s10029-013-1054-2

108. Chand B, Indeck M, Needleman B, Finnegan M, van Sickle KR, Ystgaard B, Gossetti F, Pullan RD, Giordano P, McKinley A (2014) A retrospective study evaluating the use of Permacol ${ }^{\mathrm{TM}}$ surgical implant in incisional and ventral hernia repair. Int J Surg 12:296-303. https://doi.org/10.1016/j.jjsu.214.01.025

109. Golla D, Russo CC (2014) Outcomes following placement of non-cross-linked porcine-derived acellular dermal matrix in complex ventral hernia repair. Int Surg 99:235-240. https://doi. org/10.9738/INTSURG-D-13-00170.1

110. Richmond B, Ubert A, Judhan R, King J, Harrah T, Dyer B, Thompson S (2014) Component separation with porcine acellular dermal reinforcement is superior to traditional bridged mesh repairs in the open repair of significant midline ventral hernia defects. Am Surg 80(8):725-731

111. Skipworth JRA, Vyas S, Uppal L, Floyd D, Shankar A (2014) Improved outcomes in the management of high-risk incisional hernias utilizing biological mesh and soft-tissue reconstruction: a single center experience. World J Surg 38:1026-1034. https:// doi.org/10.1007/s00268-013-2442-6

112. Yang F, Ji-Ye L, Rong L, Wen T (2015) Use of acellular dermal matrix combined with a component separation technique for repair of contaminated large ventral hernias: a possible ideal solution for this clinical challenge. Am Surg 81(2):150-156

113. Sandvall BK, Suver DW, Said HK, Mathes DW, Neligan PC, Dellinger EP, Louie O (2016) Comparison of synthetic and biologic mesh in ventral hernia repair using components separation technique. Ann Plast Surg 76:674-679. https://doi.org/10.1097/ SAP.0000000000000253

114. Ghazi B, Deigni O, Yezhelyev M, Losken A (2011) Current options in the management of complex abdominal wall defects. Ann Plast Surg 66:488-492. https://doi.org/10.1097/SAP.0b013 e. $31820 \mathrm{~d} 18 \mathrm{db}$ 


\section{Affiliations}

\section{F. Köckerling ${ }^{1}$ - N. N. Alam ${ }^{2}$. S. A. Antoniou ${ }^{3} \cdot$ I. R. Daniels ${ }^{4} \cdot$ F. Famiglietti ${ }^{5} \cdot$ R. H. Fortelny ${ }^{6} \cdot$ M. M. Heiss ${ }^{7}$. \\ F. Kallinowski ${ }^{8} \cdot$ I. Kyle-Leinhase ${ }^{9} \cdot$ F. Mayer ${ }^{10} \cdot$ M. Miserez $^{5} \cdot$ A. Montgomery ${ }^{11} \cdot$ S. Morales-Conde ${ }^{12} \cdot$ F. Muysoms $^{9}$. S. K. Narang ${ }^{4} \cdot$ A. Petter-Puchner ${ }^{13} \cdot$ W. Reinpold ${ }^{14} \cdot$ H. Scheuerlein ${ }^{15} \cdot$ M. Smietanski $^{16,20} \cdot$ B. Stechemesser ${ }^{17}$. C. Strey ${ }^{18} \cdot$ G. Woeste ${ }^{19} \cdot$ N. J. Smart ${ }^{4}$}

1 Department of Surgery and Center of Minimally Invasive Surgery, Vivantes Hospital, 13585 Berlin, Germany

2 Department of General Surgery, Manchester Royal Infirmary, Manchester, UK

3 Department of General Surgery, University Hospital of Heraklion, Heraklion, Greece

4 Exeter Surgical Health Services Research Unit, Royal Devon \& Exeter Hospital, Exeter, UK

5 Department of Abdominal Surgery, University Hospital Gasthuisberg Campus, Louvain, Belgium

6 Department of General Surgery, Wilhelminenspital, Medical Faculty, Sigmund Freud University, Vienna, Austria

7 Department of Visceral-, Vascular and Transplantation Surgery, Cologne Merheim Medical Center, University Witten/Herdecke, Cologne, Germany

8 Department of General and Visceral Surgery, Regional Hospital Bergstrasse GmbH, Heppenheim, Germany

9 Department of Surgery, AZ Maria Middelares, Ghent, Belgium

10 Department of Surgery, Paracelsus Medical University, Salzburg, Austria
11 Department of Surgery, Skåne University Hospital, Malmö, Sweden

12 Unit of Innovation in Minimally Invasive Surgery, Department of General und Digestive Surgery, University Hospital "Virgen del Rocio", Seville, Spain

13 Austrian Cluster of Tissue Regeneration, Ludwig Boltzmann Institute for Experimental and Clinical Traumatology, Vienna, Austria

14 Department of Surgery and Hernia Center, Wilhelmsburger Hospital "Gross Sand”, Hamburg, Germany

15 Department of General and Visceral Surgery, St. Vincenz Hospital, Paderborn, Germany

16 Department of Surgery \& Hernia Centre, District Hospital in Puck, Medical University of Gdansk, Gdansk, Poland

17 Hernia Center Cologne, Cologne, Germany

18 Department of Surgery, Friederiken-Hospital, Hanover, Germany

19 Department of Surgery, University Hospital, Frankfurt/Main, Germany

20 Department of Radiology, Medical University of Gdansk, Gdansk, Poland 